\title{
Thermocline Circulation in the Solomon Sea: A Modeling Study*
}

\author{
ANGÉLIQUe MELET \\ LEGI, UMR5519, CNRS, Université de Grenoble, Grenoble, France \\ LIONEL GOURDEAU \\ LEGOS, UMR5566, CNRS, IRD, UPS, Toulouse, France \\ WILLIAM S. KESSLER \\ NOAA/Pacific Marine Environmental Laboratory, Seattle, Washington \\ JACQUES VERRON AND JEAN-MARC MOLINES \\ LEGI, UMR5519, CNRS, Université de Grenoble, Grenoble, France
}

(Manuscript received 1 April 2009, in final form 17 December 2009)

\begin{abstract}
In the southwest Pacific, thermocline waters connecting the tropics to the equator via western boundary currents (WBCs) transit through the Solomon Sea. Despite its importance in feeding the Equatorial Undercurrent (EUC) and its related potential influence on the low-frequency modulation of ENSO, the circulation inside the Solomon Sea is poorly documented. A $1 / 12^{\circ}$ model has been implemented to analyze the mean and the seasonal variability of the Solomon Sea thermocline circulation. The circulation involves an inflow from the open southern Solomon Sea, which is distributed via WBCs between the three north exiting straits of the semiclosed Solomon Sea. The system of WBCs is found to be complex. Its main feature, the New Guinea Coastal Undercurrent, splits in two branches: one flowing through Vitiaz Strait and the other one, the New Britain Coastal Undercurrent (NBCU), exiting at Solomon Strait. East of the Solomon Sea, the encounter of the South Equatorial Current (SEC) with the Solomon Islands forms a previously unknown current, which the authors call the Solomon Islands Coastal Undercurrent (SICU). The NBCU, SEC, and SICU participate in the feeding of the New Ireland Coastal Undercurrent (NICU), which retroflects to the Equatorial Undercurrent, providing the most direct western boundary EUC connection, which is particularly active in JuneAugust. The Solomon Sea WBC seasonal variability results from the combination of equatorial dynamics, remotely forced Rossby waves north of $10^{\circ} \mathrm{S}$, and the spinup and spindown of the subtropical gyre as a response of Rossby waves forced south of $10^{\circ} \mathrm{S}$.
\end{abstract}

\section{Introduction}

The South Pacific low-latitude western boundary currents (LLWBCs) are seen as a major contributor to the Equatorial Undercurrent (EUC) and to the equatorial cold tongue by both observational (Tsuchiya 1981; Tsuchiya

\footnotetext{
* Pacific Marine Environmental Laboratory Contribution Number 3485.
}

Corresponding author address: Angélique Melet, Laboratoire des Ecoulements Géophysiques et Industriels, MEOM, BP 53 X, Grenoble CEDEX, France.

E-mail: melet@hmg.inpg.fr et al. 1989) and model tracer studies (Blanke and Raynaud 1997; Fukumori et al. 2004). With the South Pacific being a source of decadal variability (Luo and Yamagata 2001; Luo et al. 2003, 2005; Giese et al. 2002; Bratcher and Giese 2002; Chang et al. 2001; Holland and Raphael 2006; Nonaka and Sasaki 2007), the connections between the subtropics and the tropics through the western boundary route of the South Pacific are thought to play a major role in El Niño-Southern Oscillation (ENSO) low-frequency modulation. Despite its importance for understanding and predicting climate variability, the pathways and rates by which the western boundary currents of the southwest Pacific reach the equatorial region are very poorly documented. This is due to both the difficulty 
of observation in this far remote region of the southwest Pacific and to the difficulty of modeling the WBC route amid complex bathymetry and narrow channels.

The classical description of the southwest Pacific circulation is a westward South Equatorial Current (SEC) crossing the Pacific Ocean. It bifurcates at the Australian coast into the southward East Australian Current and the North Queensland Current (NQC) that flows north to Papua New Guinea (PNG) where it feeds the New Guinea Coastal Undercurrent (NGCU; e.g., Ridgway et al. 1993; $\mathrm{Qu}$ and Lindstrom 2002; Kessler and Gourdeau 2007).

In fact, the western boundary of the South Pacific is characterized by a complex topography, which may modify the simple circulation scheme we described earlier. The western boundary between $11^{\circ}$ and $5^{\circ} \mathrm{S}$ encompasses the Solomon Sea. This sea, located north of the Coral Sea, is bounded on the west by the island of New Guinea, on the north by the island of New Britain (NB), and on the east by the Solomon Island chain (Fig. 1). The semiclosed Solomon Sea is connected to the equator by three narrow straits [Vitiaz Strait, which is $1000 \mathrm{~m}$ deep and about $42 \mathrm{~km}$ wide at $200 \mathrm{~m}$; St. George's Channel, which is $1100 \mathrm{~m}$ deep but only about $15 \mathrm{~km}$ wide; and Solomon Strait, which is wider (about $170 \mathrm{~km}$ ) and deeper]. Its bathymetry is particularly complex, with archipelagoes, ocean basins, shallow reefs with many channels, and deep ocean trenches. The circulation in the Solomon Sea and its surroundings is relatively unknown, and the only estimates of transport through the straits come from the pioneering Western Equatorial Pacific Ocean Climate Studies (WEPOCS) cruises of 1985-86 (Lindstrom et al. 1987, 1990), from an additional cruise in 1988 (Butt and Lindstrom 1994), and from mooring buoys (Murray et al. 1995).

This study focuses on the finescale pathways of the South Pacific LLWBCs, diagnosing the thermocline circulation in the Solomon Sea and its role in the connection of subtropical/tropical thermocline water to the equator. This problem is a key issue of the Southwest Pacific Ocean Circulation and Climate Experiment (SPICE; available online at http://www.clivar.org/organization/ pacific/pacific_SPICE.php), which frames this study. Because observational diagnoses are limited by a severe lack of data, we analyze the thermocline circulation through high-resolution $\left(1 / 12^{\circ}\right)$ modeling, which is required to handle the complex bathymetry of the Solomon Sea. Given the present state of ignorance of the low-latitude WBCs in the South Pacific and more generally of the thermocline circulation in the Solomon Sea, we first examine their mean and their associated annual cycle.

This paper is organized as follows: The modeling strategy used in this study is introduced in the next section. The modeled mean thermocline circulation and its sensitivity to Vitiaz Strait bathymetry are described in section 3. The seasonal cycle is described in section 4 . The different WBCs and their connection to the EUC are discussed in section 5. Section 6 provides a summary and some concluding remarks.

\section{Models}

\section{a. High-resolution primitive equation modeling}

The high-resolution modeling of the Solomon Sea is achieved here using three distinct models nested together: a global OGCM $\left(1 / 4^{\circ}\right)$, a regional model of the southwest Pacific $\left(1 / 4^{\circ}\right)$, and a fine-grid model of the Solomon Sea $\left(1 / 12^{\circ}\right)$. All three models are based on the oceanic component of the Nucleus for European Modelling of the Ocean (NEMO) system (available online at http://www. nemo-ocean.eu/), the free-surface Ocean Parallelisé (OPA) OGCM (Madec 2008; Barnier et al. 2006). The primitive equations (PEs) are discretized on an isotropic Arakawa $\mathrm{C}$ grid, using a Mercator projection. The vertical coordinate is geopotential with 46 prescribed $z$ levels ranging from the surface to $5875 \mathrm{~m}(6-15-\mathrm{m}$ vertical resolution in the upper $100 \mathrm{~m}$ ). To improve the bathymetry representation with $z$ coordinates, a partial step parameterization (Adcroft et al. 1997) is used to allow bottom cells depth to be adaptive and to differ from the vertical prescribed levels. Mixing parameterizations are defined in Table 1.

The $1 / 4^{\circ}$ regional model of the southwest tropical Pacific extends from $140^{\circ}$ to $172^{\circ} \mathrm{E}$ and from $24^{\circ} \mathrm{S}$ to $5^{\circ} \mathrm{N}$ (Fig. 1). Its boundary conditions are provided by the $1 / 4^{\circ}$ global OGCM ORCA025-G70, developed by the DRAKKAR team (Barnier et al. 2006), using a radiative open boundary condition (OBC; e.g., Tréguier et al. 2001). The implementation of the regional model allows use of the global OGCM offline, which is cost saving, and its physical parameters can be tuned separately. In particular, the sea surface salinity (SSS) damping and the horizontal dynamic viscosity coefficient are weaker in the regional model than in the global one (Table 1) to allow the regional model to be less constrained.

The $1 / 12^{\circ}$ fine-grid model of the Solomon Sea extends from $143^{\circ}$ to $165^{\circ} \mathrm{E}$ and from $13^{\circ}$ to $0.5^{\circ} \mathrm{S}$ (Fig. 1). It is nested in the above $14^{\circ}$ regional model. Both models run interactively with two-way feedbacks based on the Adaptive Grid Refinement in FORTRAN (AGRIF) package (Debreu et al. 2008). Briefly, the two-way interactions are accomplished as follows: The $1 / 4^{\circ}$ regional model is first integrated for one time step, and the resulting fields provide the boundary conditions to the fine-grid model through spatial and temporal interpolation. Then, the fine-grid model is integrated over the same time interval, and the resulting fields are used to update the variables of the regional model via a weighted mean. To ensure 

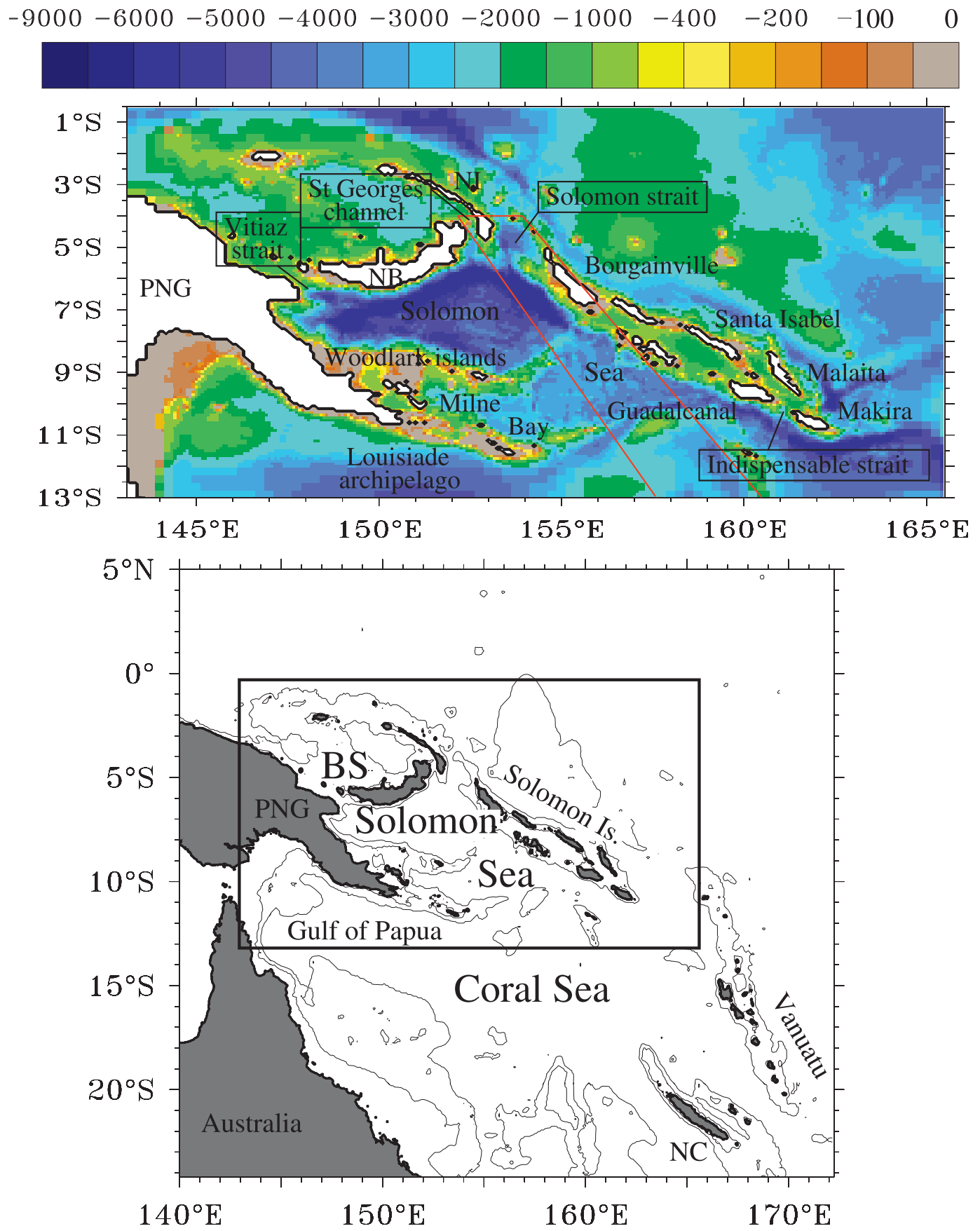

FIG. 1. Bathymetry and geography of the southwest Pacific and of the Solomon Sea: (top) $1 / 12^{\circ}$ nested fine-grid model domain and its bathymetry, where the red lines delimit the New Zealand-Japan XBT track, and (bottom) regional $1 / 4^{\circ}$ model domain and ETOPO2v1 bathymetry. Gray shading shows land and contours the 200- and 2000-m depths. The black rectangle delineates the fine-grid model domain. Island groups and seas are labeled, including Papua New Guinea (PNG), New Caledonia (NC), New Britain (NB), New Ireland (NI), and Bismarck Sea (BS).

stability of the numerical schemes, the spatial refinement between the two grids is associated with a time step refinement. Although the regional model runs with a time step of $2880 \mathrm{~s}$, the fine-grid model runs with a 3 times finer time step of $960 \mathrm{~s}$.
A finescale definition of model bathymetry is a key element to simulate the southwest Pacific, which concentrates the majority of the about 25000 Pacific islands, along with extensive reef systems and many channels. The bathymetries of the $1 / 4^{\circ}$ regional model and of the global 
TABLE 1. Subgrid diffusivity parameterization schemes and coefficients.

\begin{tabular}{|c|c|c|c|}
\hline Model & Global $1 / 4^{\circ}$ & Regional $1 / 4^{\circ}$ & Regional $1 / 12^{\circ}$ \\
\hline Hierarchy link & \multicolumn{2}{|c|}{ Nesting one way } & Nesting two ways \\
\hline Domain & Global & $24^{\circ} \mathrm{S}-5^{\circ} \mathrm{N}, 140^{\circ}-172^{\circ} \mathrm{E}$ & $13.13^{\circ}-0.5^{\circ} \mathrm{S}, 143.5^{\circ}-165.5^{\circ} \mathrm{E}$ \\
\hline
\end{tabular}

Lateral subgrid diffusivity

\begin{tabular}{llrr}
\hline Dynamics & \multicolumn{1}{c}{ Scheme } & \multicolumn{2}{c}{ Bi-Laplacian lateral geopotential viscous operator } \\
\hline $\begin{array}{l}\text { Coefficient at } 0^{\circ} \text { latitude } \\
\left(\text { decreases poleward as } \Delta y^{3}\right)\end{array}$ & $1.50 \times 10^{11} \mathrm{~m}^{4} \mathrm{~s}^{-1}$ & $1.08 \times 10^{10} \mathrm{~m}^{4} \mathrm{~s}^{-1}$ & $4.00 \times 10^{9} \mathrm{~m}^{4} \mathrm{~s}^{-1}$
\end{tabular}

Tracers

Scheme

Laplacian lateral isopycnal diffusion operator

Coefficient at $0^{\circ}$ latitude (decreases

poleward proportionally to $\Delta y$ )

$300 \mathrm{~m}^{2} \mathrm{~s}^{-1} \quad 300 \mathrm{~m}^{2} \mathrm{~s}^{-1} \quad 100 \mathrm{~m}^{2} \mathrm{~s}^{-1}$

Surface boundary and interior vertical mixing

\begin{tabular}{llcl}
\hline Dynamics/tracers scheme & Turbulent closure model (Blanke and Delecluse 1993) & \\
\hline Background vertical diffusivity & $0.01 \mathrm{~cm}^{2} \mathrm{~s}^{-1}$ & $0.01 \mathrm{~cm}^{2} \mathrm{~s}^{-1}$ & $0.01 \mathrm{~cm}^{2} \mathrm{~s}^{-1}$ \\
\hline
\end{tabular}

one are similar for consistency reasons. They are based on General Bathymetric Charts of the Oceans (GEBCO; British Oceanographic Data Centre 2003) in the upper $200 \mathrm{~m}$ and on 2-min gridded elevations/bathymetry for the world (ETOPO2v1; National Geophysical Data Centre 2001) below $300 \mathrm{~m}$, with a merge between the two bathymetric datasets between 200 and $300 \mathrm{~m}$. GEBCO is handmade from ship sounding data. ETOPO2v1 is the Smith and Sandwell (1997, hereafter SS97) product interpolated on a geographical grid instead of the original Mercator projected grid, and it is based on satellite gravity data combined with ship measurements. Note that ETOPO2v1 has a mislocation fault with a systematic one-point $\left(1 / 30^{\circ}\right)$ offset to the northeast (Marks and Smith 2006). Marks and Smith (2006) compared SS97 and GEBCO over the Woodlark Basin (Fig. 1). They state that GEBCO is smoother than SS97 and conclude that SS97 may be the best choice for many marine geoscience purposes in this area. We compared ETOPO2v1 and GEBCO with navigation charts over the whole Solomon Sea, confirming the use of ETOPO2v1 to handle the wide range of complex bathymetric features of the region (Fig. 1). To elaborate the bathymetry of the fine-grid model, the bathymetric data on the ETOPO2v1 grid have been interpolated using a median mean on the $1 / 12^{\circ}$ resolution grid over the Solomon Sea. The resulting bathymetry has been checked and hand modified if necessary in the key regions of the Solomon Sea using navigation charts.

The regional and fine-grid models are forced in the same way with the datasets used to force the global ORCA025G70 model (Barnier et al. 2006). At the surface, the atmospheric fluxes of momentum, heat, and freshwater are diagnosed through classical bulk formulas (Large and Yeager 2008). Realistic winds and atmospheric temperature and humidity are provided by the $40-\mathrm{yr}$ European Centre for Medium-Range Weather Forecasts (ECMWF) Re-Analysis (ERA-40; 6-h fields; Uppala et al. 2005). Precipitation (monthly fields) and longwave and shortwave radiation (daily fields) are provided by the Common Ocean-Ice Reference Experiments (CORE) dataset, developed by Yeager and Large (2004) at the National Center for Atmospheric Research (NCAR). Both models are initialized with the climatological mass field of the World Ocean Atlas 1998 (WOA98; Levitus et al. 1998), and were integrated over the 1984-2004 period. Outputs consist of daily means for both models. An initial period of $2 \mathrm{yr}$ was used for the adjustment of the model. Thus, the 1986-2004 period was used to produce a climatology and a monthly average annual cycle.

\section{b. Model performance}

We were aware of a possible influence of the boundary conditions on the EUC simulation. We checked that the $\mathrm{OBC}$ in the regional $1 / 4^{\circ}$ regional model and the location of the northern boundary of the $1 / 12^{\circ}$ nested model are not implying faults in the EUC modeling.

The model performance is evaluated using several in situ datasets. Zonal currents from the Tropical Atmosphere Ocean (TAO; available online at http://www.pmel. noaa.gov) buoy at $0^{\circ}, 165^{\circ} \mathrm{E}$ available during the $1986-93$ period are used to evaluate the EUC representation in the $1 / 4^{\circ}$ regional model (Fig. 2). Even if the EUC is slightly weaker in the model than in the observations, both the annual cycle and interannual variability are well captured in the model. In both, the EUC was found to be stronger in austral winter and weaker in austral summer, and it was particularly strong in 1988-89. 

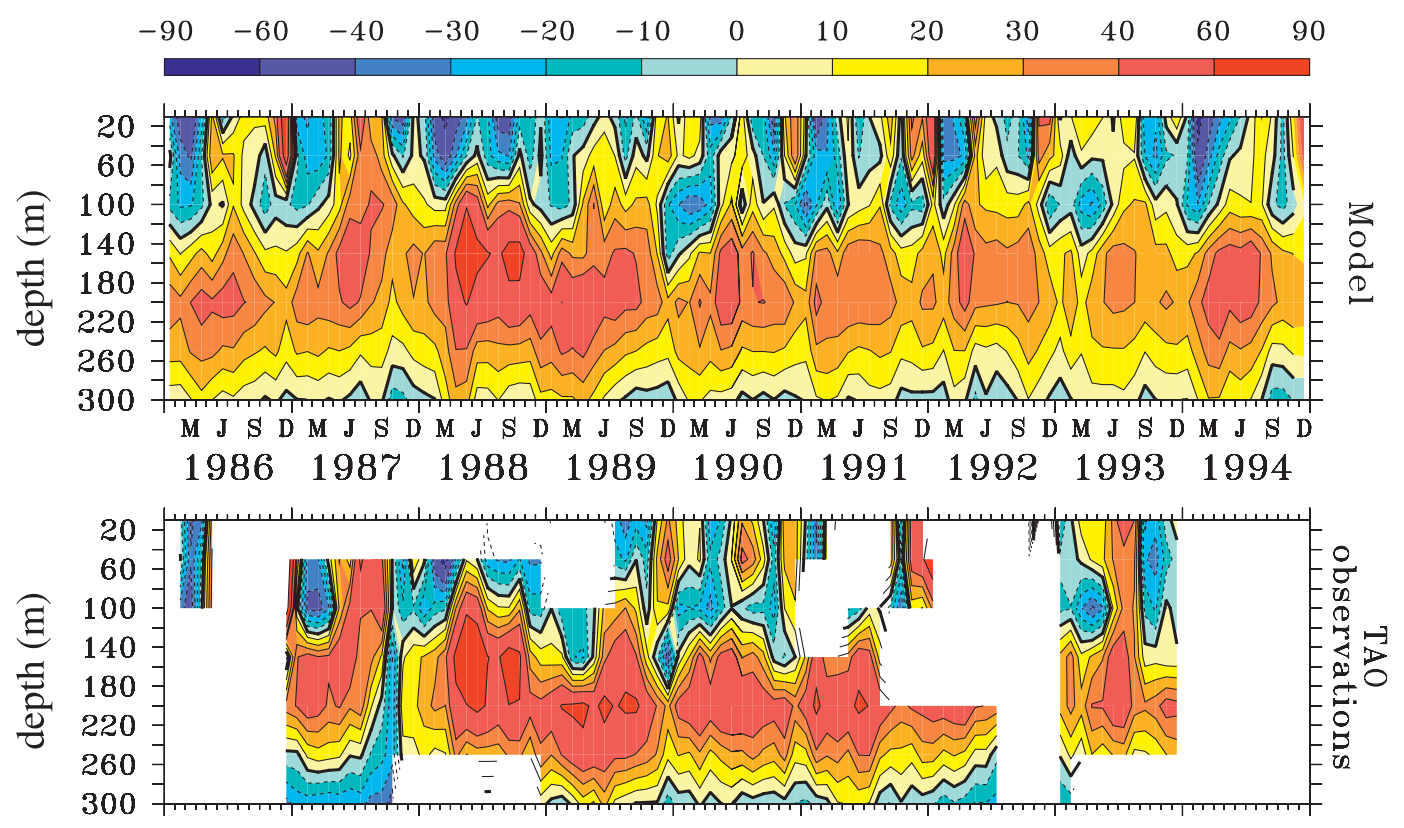

FIG. 2. Zonal current $\left(\mathrm{cm} \mathrm{s}^{-1}\right)$ at $0^{\circ}, 165^{\circ} \mathrm{E}$ for (top) the model and (bottom) TAO data.

A New Zealand-Japan XBT track crosses the western Solomon Sea to Solomon Strait (Fig. 1) and was frequently repeated over the 1986-99 period. A comparison of the mean modeled temperature with the observed XBT fields shows that both the mean state and the interannual variability of the thermocline temperature in the Solomon Sea are fairly well reproduced by the model (Fig. 3). The interannual variability is dominated by El Niño-Southern Oscillation, with notably warm anomalies the years preceding El Niño events.

Finally, transports entering and exiting the Solomon Sea have been observed during several oceanographic cruises (Lindstrom et al. 1990; Butt and Lindstrom 1994; Murray et al. 1995; Sokolov and Rintoul 2000). The observed and correspondingly modeled transports are presented in Table 2. Analyzing the World Ocean Circulation Experiment (WOCE) section at $155^{\circ} \mathrm{E}$ (P11), Sokolov and Rintoul (2000) found a net top-to-bottom NQC transport of $26 \mathrm{~Sv}\left(1 \mathrm{~Sv} \equiv 10^{6} \mathrm{~m}^{3} \mathrm{~s}^{-1}\right)$ in June-July 1993. In our simulation, the corresponding NQC transport is $28 \mathrm{~Sv}$, which is in good agreement with the observations. The modeled St. George's Channel transport appears to be too weak, with about half the observed transport, whereas the modeled NICU transport is stronger than the observed one. The comparison of the model with Vitiaz Strait available observations of Lindstrom et al. (1990), Butt and Lindstrom (1994), and Murray et al. (1995) shows that the modeled Vitiaz Strait transports (VS) are in good agreement with the observations, both in terms of top-to-bottom and thermocline transports.
Thus, the model seems to realistically represent the annual and interannual variability of temperature and transports in the thermocline layer. More specific comparisons of the model to available observations will be presented in sections 3 and 5 .

\section{Mean thermocline circulation}

The thermocline is of major interest here because the LLWBCs of the South Pacific all have subsurface maxima (Lindstrom et al. 1987, 1990; Butt and Lindstrom 1994). For the purpose of this study, the thermocline is defined by the 24.0-26.5-sigma layer. The depths of these isopycnal surfaces vary from 100 to $400 \mathrm{~m}$, depending on time and space. This density range encompasses the main modeled undercurrent cores and the 25.0-sigma isopycnal surface characterizing the core of the EUC (Johnson and McPhaden 1999).

\section{a. Description of the circulation}

The 1986-2004 thermocline circulation as modeled by the fine-grid model is shown in Fig. 4a. In the open southwest Pacific, the SEC forms the northern branch of the subtropical gyre (Kessler and Gourdeau 2007). The SEC is a broad westward current extending from $2^{\circ} \mathrm{N}$ to $30^{\circ} \mathrm{S}$. It bifurcates against the western boundary, forming WBCs as expected from the wind-driven island rule theory (Godfrey 1989; Webb 2000; Kessler and Gourdeau 2007).

North of $10^{\circ} \mathrm{S}$, the encounter of the SEC with the Solomon Islands and New Ireland (NI) coasts results in equatorward return flow through two partly connected WBCs: a 

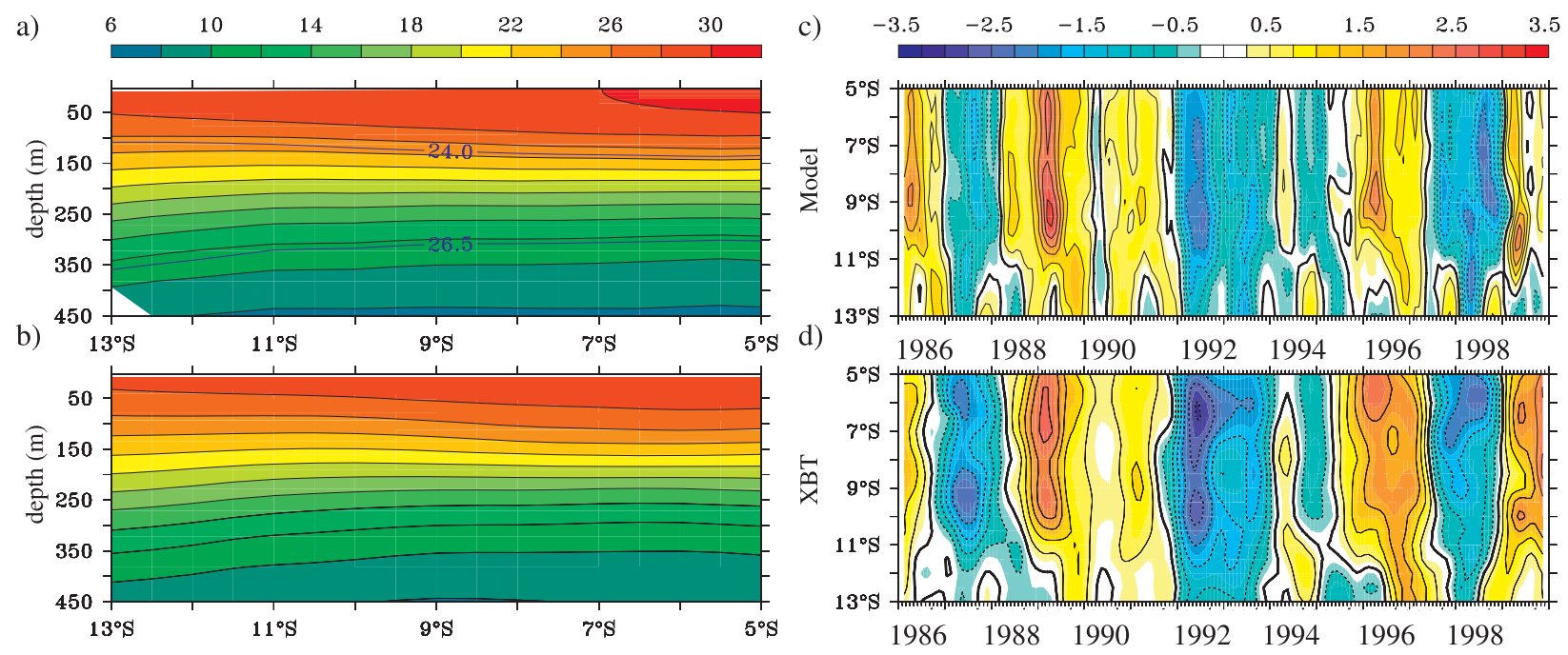

FIG. 3. New Zealand-Japan XBT track. Mean temperatures along the track for (a) the model and (b) the XBT observations. Interannual thermocline (130-310 m) temperature anomalies for (c) the model and (d) the XBT observations. Temperatures are given in ${ }^{\circ} \mathrm{C}$. Blue lines in (a) represent the depth of the modeled isopycnal 24.0 and 26.5 surfaces. The mean and anomalies are relative to the 1986-99 period, over which the XBT time coverage was good. The location of the track appears in Fig. 1.

current flowing along the Solomon Islands that we propose to name the Solomon Islands Coastal Undercurrent (SICU) and the New Ireland Coastal Undercurrent (NICU). The NICU has been observed, and an initial description is given by Butt and Lindstrom (1994). The SICU has never been observed; it was just mentioned as a possible current in the model study by Kessler and Gourdeau (2007). The Solomon Islands north of Guadalcanal at $10^{\circ} \mathrm{S}$ (Fig. 1) is essentially a solid barrier; however, south of this, a filament of the SEC directly enters the Solomon Sea through Indispensable Strait (Fig. 1). Near $15^{\circ} \mathrm{S}$, the SEC splits around the Vanuatu Archipelago (Fig. 1) forming at its northern tip $\left(13^{\circ} \mathrm{S}\right)$ the North Vanuatu Jet (NVJ) (Webb 2000; Kessler and Gourdeau 2007; Gourdeau et al. 2008; Couvelard et al. 2008; Qiu et al. 2009). The northern NVJ turns north and directly enters the Solomon Sea between Guadalcanal and the Louisiade Archipelago. The remainder flows westward.

Farther west, the SEC bifurcates along the Australian coast (Kessler and Gourdeau 2007). The resulting equatorward WBC, the NQC, flows along the Australian coast up to the Gulf of Papua. One can note the meanders of the NQC in the Gulf of Papua and the eddy created there before the NQC turns eastward along the south coast of New Guinea (Fig. 4a). The NQC turns sharply around the tip of the Louisiade Archipelago to enter the Solomon Sea as a narrow boundary-trapped current and then combines with the NVJ to form the main Solomon Sea WBC, the NGCU. This powerful current occupies the western part of the Solomon Sea, whereas the eastern part is characterized by weaker eddies and recirculations. A part of the NGCU flows along the PNG coast in the semiclosed Milne Bay, and the remainder of NGCU waters flow offshore, just east of Milne Bay, in the central Solomon Sea. North of the Woodlark Islands (Fig. 1), the NGCU is reunited and flows northwestward along the New Guinea coast toward the mouth of Vitiaz Strait.

As it approaches the entrance to Vitiaz Strait, the NGCU splits into two branches. One branch flows through the strait and northwestward along the northern coast of New Guinea to the far western Pacific. This branch has been repeatedly observed (Toole et al. 1988; Tsuchiya et al. 1989; Lindstrom et al. 1990; Butt and Lindstrom 1994; Fine et al. 1994; Lukas et al. 1996; Kuroda 2000) and is still referred

TABLE 2. Observed/correspondingly modeled transports (in Sv) entering or exiting the Solomon Sea estimated from oceanographic cruises.

\begin{tabular}{lccr}
\hline \hline Transport in Sv (observed/modeled) & Vitiaz Strait & St. George's Channel & NICU \\
\hline Murray et al. (1995) & $15.8 / 16.0$ & - & - \\
Lindstrom et al. (1990): January 1986 & $6.6 / 7.1$ & $2.0 / 0.8$ & - \\
Lindstrom et al. (1990): May 1988 & $5.6 / 7.8$ & $2.7 / 1.4$ & - \\
Butt and Lindstrom (1994) & $4.3 / 4.6$ & $2.5 / 1.3$ & - \\
Sokolov and Rintoul (2000) & - & - & - \\
\hline
\end{tabular}



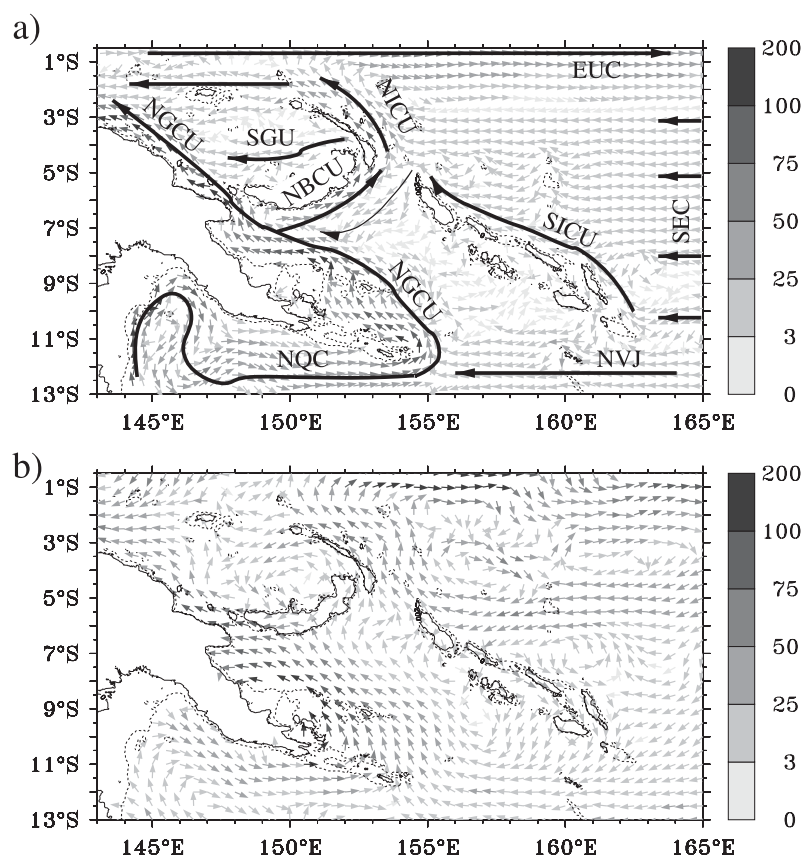

FIG. 4. Solomon Sea circulation vertically integrated over the thermocline (defined by the 24.0-26.5 isopycnal layer) from (a) the fine-grid model (1986-2004 mean) and (b) the CARS climatology (geostrophy relative to $1100 \mathrm{~m}$ ). Units are in $\mathrm{m}^{2} \mathrm{~s}^{-1}$. The main undercurrents are labeled in (a).

to as the NGCU. The other branch is a previously undescribed current flowing eastward along the southern coast of New Britain. This current has only been hinted at in previous studies (Inoue and Welsh 1993; Ridgway et al. 1993; Fine et al. 1994). We propose to name it the New Britain Coastal Undercurrent (NBCU).

A small part of the NBCU exits the Solomon Sea through the narrow St. George's Channel (Fig. 1), forming the St. George's Undercurrent (SGU; Lindstrom et al. 1990; Butt and Lindstrom 1994), but its major flow exits the Solomon Sea through the wider Solomon Strait (note that the surface flow in Solomon Strait is reversed, flowing westward into the Solomon Sea). At thermocline level, the eastward NBCU directly feeds the NICU (Butt and Lindstrom 1994), joining with the equatorwardflowing SICU and additional contributions from the lowlatitude SEC. After flowing equatorward along the New Ireland coast to its tip at $2^{\circ} \mathrm{S}$, the NICU splits in two branches. One branch turns westward into the Bismarck Sea (BS), eventually joining the NGCU along the northern coast of New Guinea. The second branch is directly retroflected into the eastward EUC. This last route appears to be the most direct connection for the thermocline Solomon Sea water to the EUC.

To check the realism of our high-resolution model, the mean thermocline circulation is assessed using the
Commonwealth Scientific and Industrial Research Organisation (CSIRO) Atlas of Regional Seas (CARS; Ridgway et al. 2002). This is the most relevant climatological dataset for the southwest Pacific, even though the complex bathymetry of the Solomon Sea is not fully taken into account during the spatial interpolation of the relatively sparse data available.

Mean geostrophic currents relative to $1100 \mathrm{~m}$ were computed from the CARS mass field. CARS geostrophic velocities vertically integrated over the thermocline layer are shown in Fig. 4b. The CARS climatology provides a relatively coarse resolution that is inadequate to represent the fine scales of the Solomon Sea. Nevertheless, the CARS currents retrieve most of the thermocline circulation structures described above, though some differences exist. The NGCU is broader in the coarse CARS climatology, taking up nearly the whole Solomon Sea. Its bifurcation along New Britain occurs farther east in CARS than in the model solution, leading to a weaker NBCU. Given the weaknesses of the climatology that is insufficient for validation of the fine features represented in the model, the comparison shows that the main features of the observed thermocline circulation are correctly reproduced in the model.

\section{b. Sensitivity of the circulation to Vitiaz Strait bathymetry}

We suspect that the existence of the NBCU is a consequence of transport limitation through Vitiaz Strait, related to its narrowness or depth restriction. To evaluate this assumption, the depth and width of Vitiaz Strait have been modified in a series of test experiments, and the model was run for $1 \mathrm{yr}$ with the different geometries. The observed bathymetry at Vitiaz Strait gives a sill of roughly 1000-m depth with a width of $42 \mathrm{~km}$ at $200 \mathrm{~m}$ (e.g., Lindstrom et al. 1990). Experiments deepening the strait showed that this has little impact on the thermocline flow, probably because the lower thermocline is well above the bottom. However, a 25-km (about 60\%) widening of Vitiaz Strait leads to a significant modification of the NGCU partition: Vitiaz Strait thermocline transport increases while the NBCU transport decreases accordingly, and this directly affects the SGU and the NICU transports (Fig. 5). In turn, the NICU splitting north of New Britain is modified, with almost all the NICU being retroflected in the EUC in the widened Vitiaz Strait case.

To evaluate the impact of model dissipation on Vitiaz Strait thermocline transport and on the NBCU existence, we performed another sensitivity experiment to model dissipation. A 4-time decrease of the lateral dynamics eddy viscosity, which is the dominant dissipation coefficient (Table 1), does not significantly change the partition of 


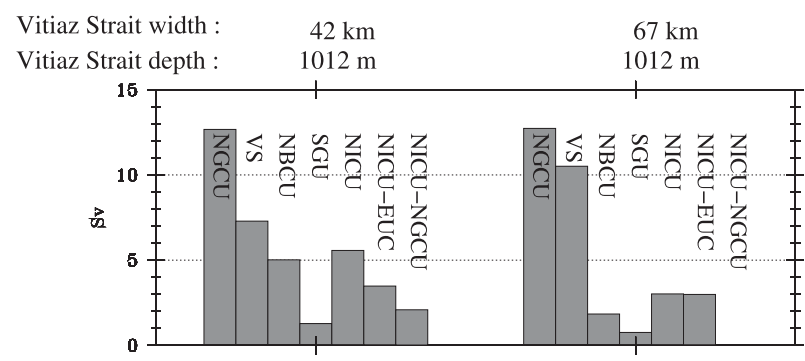

FIG. 5. Sensitivity of the thermocline circulation to Vitiaz Strait bathymetry. (left) In the first experiment (run of reference), the strait geometry is very similar to the reality (42 km wide and $1012 \mathrm{~m}$ deep). (right) In the second experiment, the strait is widened (to $67 \mathrm{~km}$ ), leading to an increase of VS and a decrease of the NBCU, NICU, and SGU transports. The sections defining the different currents are presented in Fig. 9.

the thermocline transport of the NGCU between Vitiaz Strait and the NBCU (the Vitiaz Strait versus NBCU thermocline transport ratio is increased by only $7 \%$ ). So, if model dissipation influences the NBCU transport, it does not invalidate the conclusion that the NBCU is primarily due to the limitation of the thermocline transport in Vitiaz Strait, and the controlling factor is the narrow width of the strait, not its depth. As a consequence, the bathymetry of Vitiaz Strait is an important limiting factor that can modify the different paths from the Solomon Sea to the EUC. Thus, a realistic representation of Vitiaz Strait bathymetry is fundamental to correctly model the Solomon Sea circulation and its connections to the EUC. Limitation of thermocline transport by the bathymetry could also be important in other parts of the Solomon Sea: for example, the Woodlark Islands, which also seem to determine the partition of the NGCU between different pathways (Fig. 4a).

\section{The annual cycle}

\section{a. Harmonic analysis}

A synthetic representation of the annual cycle of thermocline circulation is made using the methodology described in Kessler and Gourdeau (2007) and is summarized here. First, the dominant annual signal is extracted and represented by variance ellipses (Fig. 6a). The major and minor axes of a variance ellipse are the standard deviations of the perpendicular velocity components after the ellipse has been rotated to express the maximum possible variance in the direction of the major axis (see Preisendorfer 1988). The advantage of this rotation is that it defines a velocity that encompasses both the zonal and meridional components in a single quantity, according to the direction of maximum variance. By definition, the major axis velocity component accounts for at least $50 \%$ of the total annual variance (usually a much larger fraction, especially where the annual variance is large; note the elongation of most of the ellipses in Fig. 6a), and we use the major axis alone to define the signal of interest. The second step is to decompose the major axis velocity component into its 1 cycle per year (cpy) harmonic components, yielding an amplitude and phase at each point. These efficiently describe the annual cycle (Fig. 6b). Because of the $180^{\circ}$ ambiguity of the major ellipse axis direction, each vector can be reversed with a corresponding phase lag of 6 months.

In most cases, the variance ellipses (Fig. 6a) are strongly elongated in the direction of the mean flow (Fig. 4a) and their magnitudes are high where mean currents are high (EUC, SEC, WBCs). Thus, the variance ellipses represent a seasonally varying EUC, SEC inflow to the western boundary region, and a corresponding seasonal variability of the WBCs.

The SEC and EUC variabilities at annual time scales have already been emphasized by several studies. At the equator, the annual march of the intertropical convergence zone (ITCZ) explains the seasonal variability of the EUC through equatorial Kelvin and Rossby waves (Yu and McPhaden 1999). Off the equator and north of $10^{\circ} \mathrm{S}$, the same wind forcing induces prominent annual wind stress curl variations that excite a remotely forced Rossby wave regime (Wang et al. 2000). As the seasonal wind forcing and the ocean response propagate westward at similar speeds, the Rossby waves can be resonantly enhanced (Chen and Qiu 2004).

The role of annual Rossby wave dynamics in the SEC variability is illustrated in Fig. 6b. East of the Solomon Sea, the date of maximum SEC lags from February at $3^{\circ} \mathrm{S}$ to October at $10^{\circ} \mathrm{S}$. This phase lag as a function of latitude reflects the decrease of the Rossby wave speed with latitude. To highlight the timing and nature of the Rossby wave dynamics east of the Solomon Sea, a Hovmöller diagram of modeled sea level anomalies (SLA) and zonal thermocline transports averaged between $167^{\circ}$ and $170^{\circ} \mathrm{E}$ in the $1 / 4^{\circ}$ regional model is presented in Fig. 7. The SLA shows downwelling and upwelling Rossby waves arriving successively at latitudes spanning the Solomon IslandsNew Ireland. These Rossby waves induce geostrophic velocity anomalies, and the westward thermocline transport is enhanced from March $\left(3^{\circ} \mathrm{S}\right)$ to October $\left(10^{\circ} \mathrm{S}\right)$, whereas it is minimum from July $\left(3^{\circ} \mathrm{S}\right)$ to April $\left(10^{\circ} \mathrm{S}\right)$.

The NICU/SICU seasonal variability directly responds to the Rossby wave regime forcing and also to the equatorial variability. On the one hand, mass conservation implies that EUC modulation controls how much of the NICU/SICU can retroflect to the equator. An increase of the EUC $(d u / d x>0)$ will pull NICU waters to the equator (otherwise, these signals will propagate westward from the 

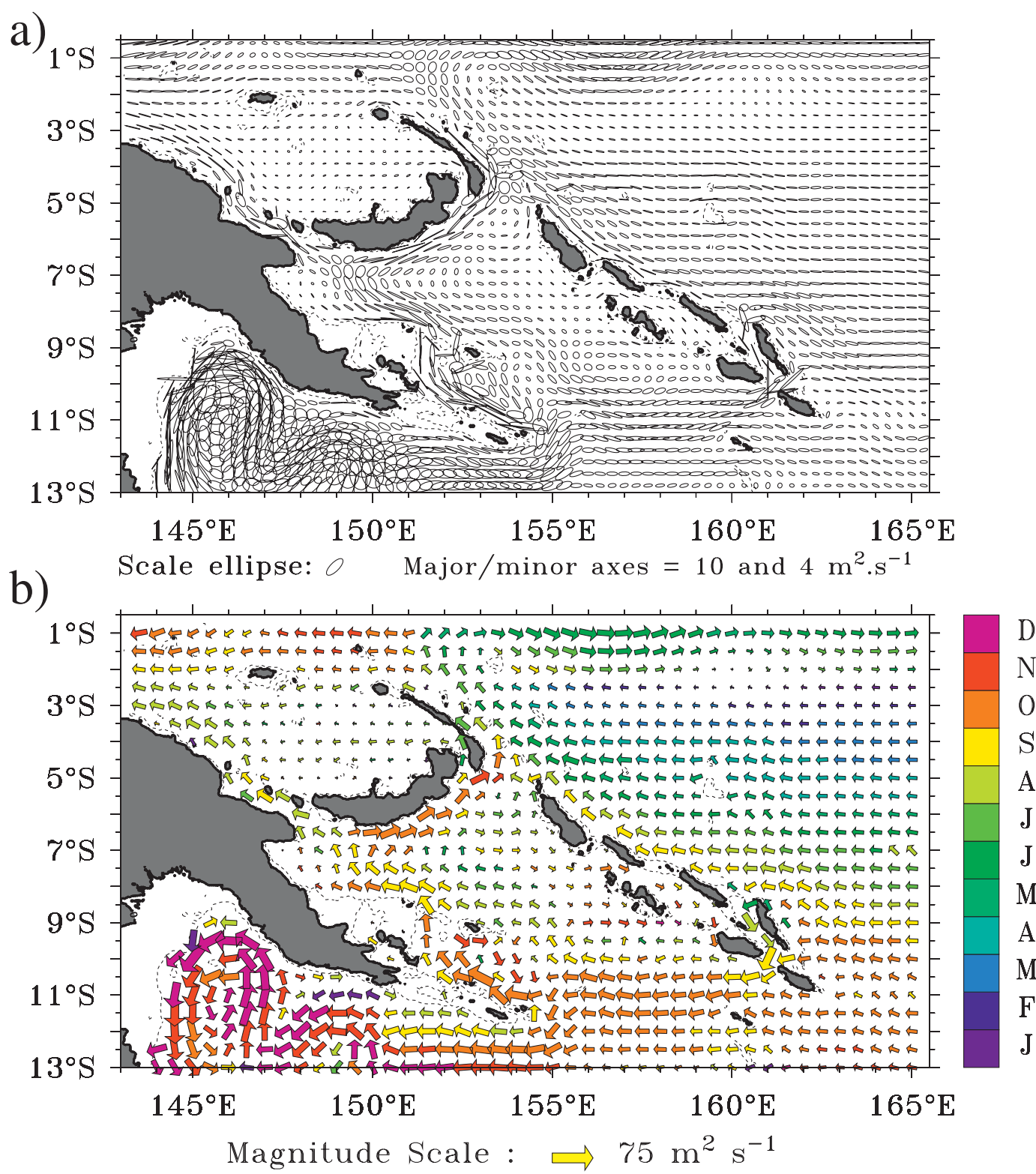

FIG. 6. The annual cycle of the thermocline transport in the fine-grid model: (a) variance ellipses and (b) 1-cpy harmonic analysis of the thermocline circulation. The area of each vector indicates the magnitude of the 1-cpy harmonic, the direction points along the major axes of the corresponding variance ellipse (i.e., the direction of maximum variance, not the direction of mean flow a priori), and the color indicates the month of maximum transport in the direction of the vector. The choice of vector direction is arbitrary: each vector could be reversed and its phase advanced by 6 months to show the opposite phase of annual anomalies.

tip of New Ireland). On the other hand, the wind-driven Rossby waves over the off-equatorial region control the direct response of the WBC to the interior ocean incoming flow. Those two forcing elements, as well as their relative phasing, produce the annual cycle of the NICU and SICU transports as shown in next section.

South of $10^{\circ} \mathrm{S}$, Chen and Qiu (2004) and Kessler and Gourdeau (2007) showed that the annual march of the
South Pacific convergence zone (SPCZ) induces large wind stress variability in the subtropical South Pacific, and the shape of annual variations of the wind generates a stationary, in-phase Rossby solution in the western subtropics. This spatially and temporally quite uniform oceanic response to wind forcing results in a spinup (in austral spring) and spindown (in austral fall) of the western subtropical gyre. As a consequence, the northern branch 
a)

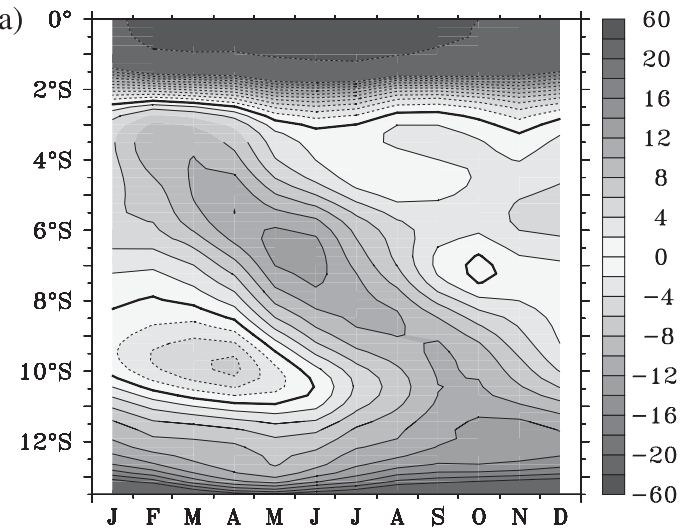

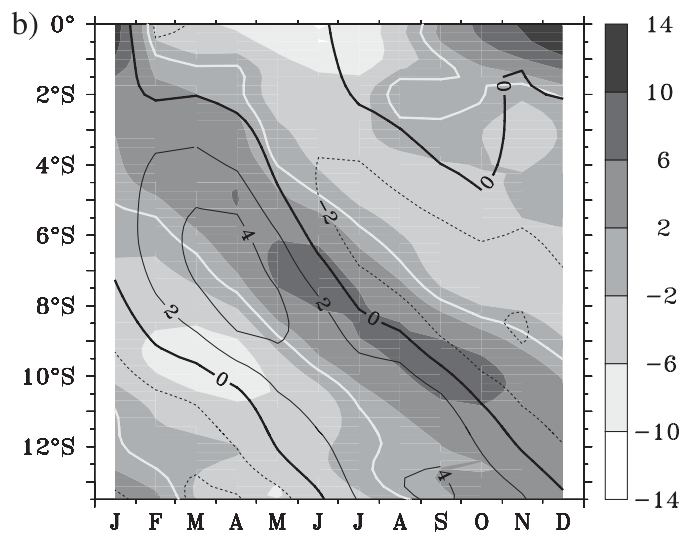

FIG. 7. Time-latitude diagram of the zonal velocity vertically integrated over the thermocline layer and averaged between $167^{\circ}$ and $170^{\circ} \mathrm{E}$ in the regional $1 / 4^{\circ}$ model. Transports $\left(\mathrm{m}^{2} \mathrm{~s}^{-1}\right)$ are positive westward in the direction of the mean flow: (a) absolute transport, where the line contours indicate positive (westward) transports and the dashed contours indicate negative (eastward) transports; and (b) transport anomalies (color). Note that the color bar is not centered. The white line delineates the negative (eastward) anomalies from the positive (westward) anomalies. SLA values are superimposed (2-cm contour line).

of the gyre exhibits westward anomalies in austral spring, with a corresponding increase of the westward-flowing NVJ and a decrease of the eastward-flowing NQC. We recover those results in our model, with maximum westward transport anomalies that are almost in phase south of $10^{\circ} \mathrm{S}$ east of New Guinea (Fig. 6b). This is consistent with the results of Kessler and Gourdeau (2007) showing that, south of $10^{\circ} \mathrm{S}$ in the western Pacific, a stationary, inphase Rossby wave regime prevails.

The annual cycle of the western boundary currents of the Solomon Sea responds to the basinwide wind forcing, which modulates incoming and outgoing transports of the EUC, the SEC, and the NVJ. Although the interior ocean forcing presents a fairly simple pattern as described above, the boundary response is more intricate because of the shape of the coast and of the lags introduced by Rossby wave phase propagation (Rossby waves arriving at the northeastern Australian coast at $145^{\circ} \mathrm{E}$ travel farther and at lower speed than those arriving at the Solomon Islands coast at $160^{\circ} \mathrm{E}$ ). As these waves arrive at the coast, they generate equatorwardpropagating coastal Kelvin waves that modulate the inshore-offshore pressure gradients and thereby affect the boundary currents to the north (Godfrey 1975; Kessler and Gourdeau 2007).

Figure $6 \mathrm{~b}$ illustrates the complexity of the seasonal variability of circulation in the Solomon Sea. For instance, the NGCU is at maximum in October in Milne Bay, in phase with the NVJ, whereas the eastern part of the NGCU flowing in the central Solomon Sea is advanced in phase, with a maximum transport in August-September. North of the Woodlark Islands, the NGCU is at maximum in September. In the northern Solomon Sea, the two branches of the NGCU have different timing. The NGCU is at maximum in August along the northern coast of New Guinea, in phase with the NICU, whereas the NBCU is at maximum in October.

In the following section, the circulation in each season is described.

\section{b. Seasonal circulation}

Figure 8 shows the seasonal average anomaly of velocity fields vertically integrated over the thermocline layer. All the main undercurrents in the Solomon Sea are modulated at seasonal cycle, although none of them reverse. In this section, we describe the different current annual cycles by considering the mass redistribution involved in the complex interactions between off-equatorial Rossby waves and the equatorial dynamics.

\section{1) FeBruARY-APRIL}

In austral fall, the western subtropical gyre spins down (section 4a), leading to a clockwise anomalous circulation and an increase of the NQC and a decrease of the NVJ (Kessler and Gourdeau 2007). At the same time, the remotely forced Rossby regime east of the Solomon Sea is anomalously removing water from the boundary between $7^{\circ}$ and $11^{\circ} \mathrm{S}$ and leads to an intensified SEC at the latitudes of Solomon Strait. This seasonally strong SEC inflow combined with a weaker than usual NVJ inflow implies a weakening of the Solomon Sea boundary currents. Westward anomalies are found in the NBCU, and the NGCU exhibits southeastward anomalies both in the Solomon Sea and along the northern coast of New Guinea. In the same way, the western boundary currents along the 


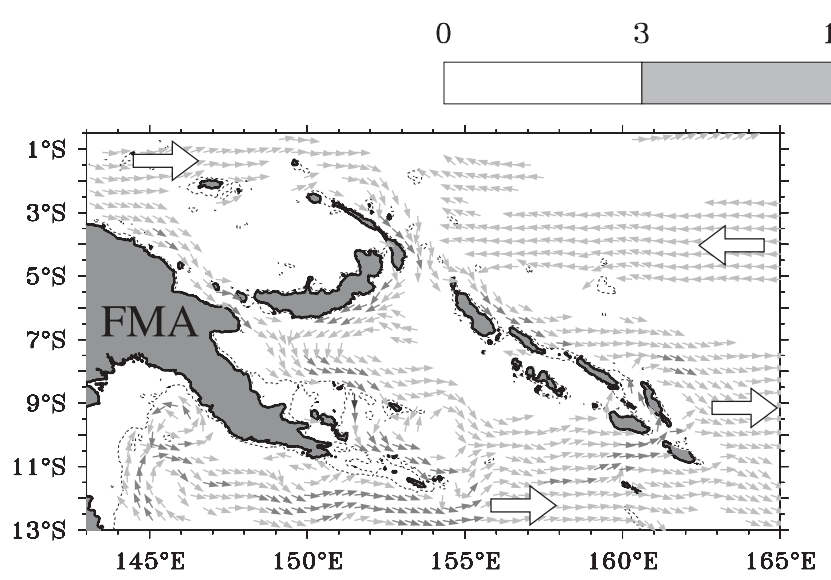

$10 \quad 25$

50
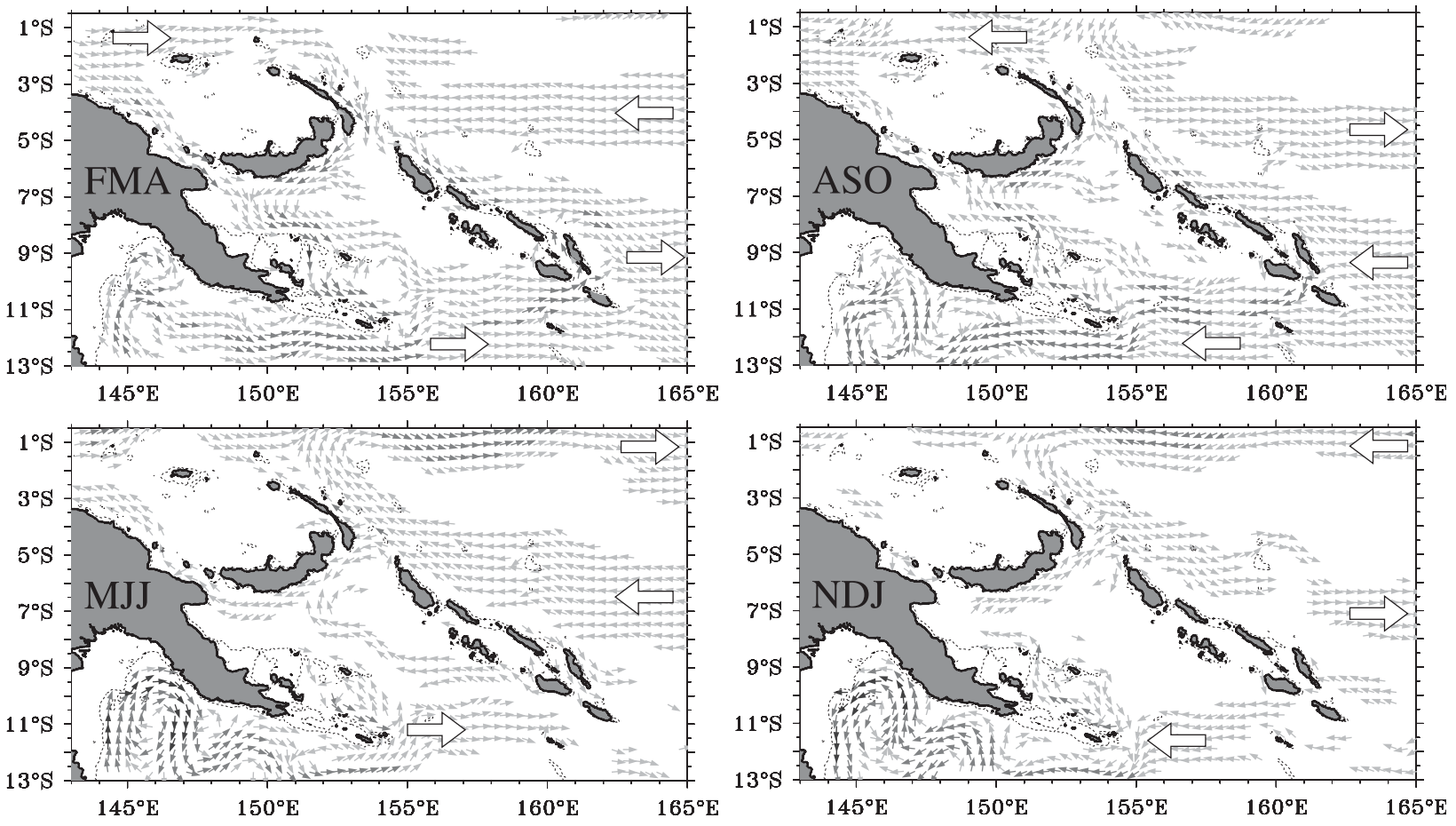

FIG. 8. Three-month averages of annual anomalies of the modeled thermocline circulation. Units are in $\mathrm{m}^{2} \mathrm{~s}^{-1}$. White large arrows schematically highlight the role of wind forcing outside the Solomon Sea.

entire east coast of the islands, the NICU, and the SICU are anomalously southward (weak) in austral fall.

\section{2) MAY-JULY}

As the basinwide winds shift south in austral winter, the SEC maximum also moves south, to $5^{\circ}-8^{\circ} \mathrm{S}$ (Fig. 7), while eastward EUC anomalies develop. The NICU becomes anomalously strong, as a response to this forcing: the EUC pulls more water from the NICU and the SEC feeds more water to the western boundary north of $8^{\circ} \mathrm{S}$. This is like a strengthening of the mean pattern, and as a result mass conservation implies that the NICU must be anomalously equatorward (Fig. 8). As the SEC maximum shifts south, increased westward flow through Indispensable Strait begins to leak into the Solomon Sea.

In the subtropics, the subtropical gyre lingers in its spindown phase, with eastward anomalies continuing along the southern entrance to the Solomon Sea, fed by a large NQC northward flow. This contributes to the initiation of northward flow in the NGCU.

\section{3) August-October}

In austral spring, the subtropical gyre fully spins up, with anticyclonic anomalies that encompass the entire subtropical gyre (Kessler and Gourdeau 2007). Consequently, the westward NVJ is maximum and the northward coastal NQC is minimum (Fig. 8). East of the Solomon Sea, the basinwide wind forcing generates eastward (weakening) anomalies in the SEC between $3^{\circ}$ and $6^{\circ} \mathrm{S}$ and westward anomalies in the SEC south of $8^{\circ} \mathrm{S}$. Essentially, the windforced interior circulation anomalies have slid southward from the previous season. In response to this SEC transport, Solomon Sea inflow through Indispensable Strait is at maximum. Moreover, the SICU northward anomalies strengthen and extend along the entire Solomon Island chain. Meanwhile, westward anomalies develop in the EUC. The western boundary mass is no longer being pulled by the EUC, and the NICU exhibits only small anomalies. In the Solomon Sea, the anomalously strong inflow through both the NVJ and Indispensable Strait is transmitted to both the NGCU at Vitiaz Strait and the NBCU.

\section{4) NOVEMBER-JANUARY}

In austral summer, the EUC has reached its seasonal minimum; as the wind pattern continues to slide southward, eastward anomalies of the SEC move to $8^{\circ} \mathrm{S}$ east of the Solomon Sea (Fig. 7). To connect these patterns, southward anomalies develop in the NICU and in the SICU. South of the Solomon Sea, the NVJ is still stronger 


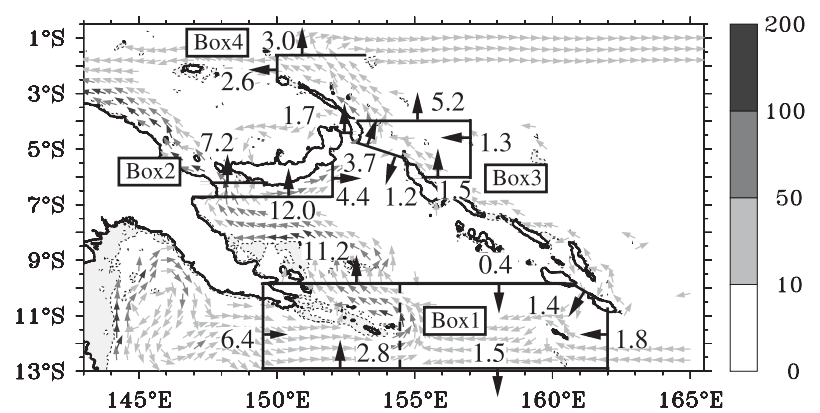

FIG. 9. Definition of the different boxes used to analyze the thermocline transports in the Solomon Sea. For each section of each box, the mean transport (in Sv) is given. Transports are positive in the direction of the mean flow, as denoted by the arrows for each section. Box 1 is defined to analyze the flux at the southern boundary of the Solomon Sea. The dashed line indicates the $154.5^{\circ} \mathrm{E}$ longitude, which splits the northern and southern boundary transports in the text. Box 2 is defined to analyze the splitting of the NGCU at Vitiaz Strait. Box 3 is defined to analyze the flux at Solomon Strait. Box 4 is defined to analyze the retroflection of the NICU to the EUC. The background illustrates the climatological thermocline circulation as shown in Fig. 4.

than usual because of the gyre spinup. It feeds equatorward anomalies in the NGCU in the western Solomon Sea, which are first transmitted to the NBCU. The stronger than usual NBCU compensates for the anomalous removal of water by the SEC from the western boundary east of the Solomon Sea.

\section{Details of the WBCs}

Here, we define several regional boxes to identify the varying transports and sources of each of the major currents. For this purpose, four boxes are defined and presented in Fig. 9. The mean transports through the different sections are also given. The convention used is that the transports are taken positive in the direction of the mean flow (given by the arrows at each section of the different boxes).

\section{a. Box 1: Southern Solomon Sea inflow (Fig. 10)}

Qu and Lindstrom (2002) gave evidence for the NQC feeding the NGCU through and around the Louisiade Archipelago. They found that the maximum speed of the flow $\left(>8 \mathrm{~cm} \mathrm{~s}^{-1}\right)$ lies at $200-300 \mathrm{~m}$. In our simulation, the core of the $\mathrm{NGCU}$ at $10^{\circ} \mathrm{S}$ is located west of $154.5^{\circ} \mathrm{E}$, in Milne Bay, with speeds of $20 \mathrm{~cm} \mathrm{~s}^{-1}$ in the $100-300-\mathrm{m}$ depth range. Note that the NGCU extends well below the 26.5 isopycnal, in this and other sections (Figs. 10, 11). This is due to the NQC source of the NGCU. Indeed, although the NVJ mainly flows above $500 \mathrm{~m}$ (Kessler and Gourdeau 2007), the NQC extends much deeper.

In the model, at $10^{\circ} \mathrm{S}$, the net mean thermocline transport into the Solomon Sea is $10.8 \mathrm{~Sv}$, and the NGCU

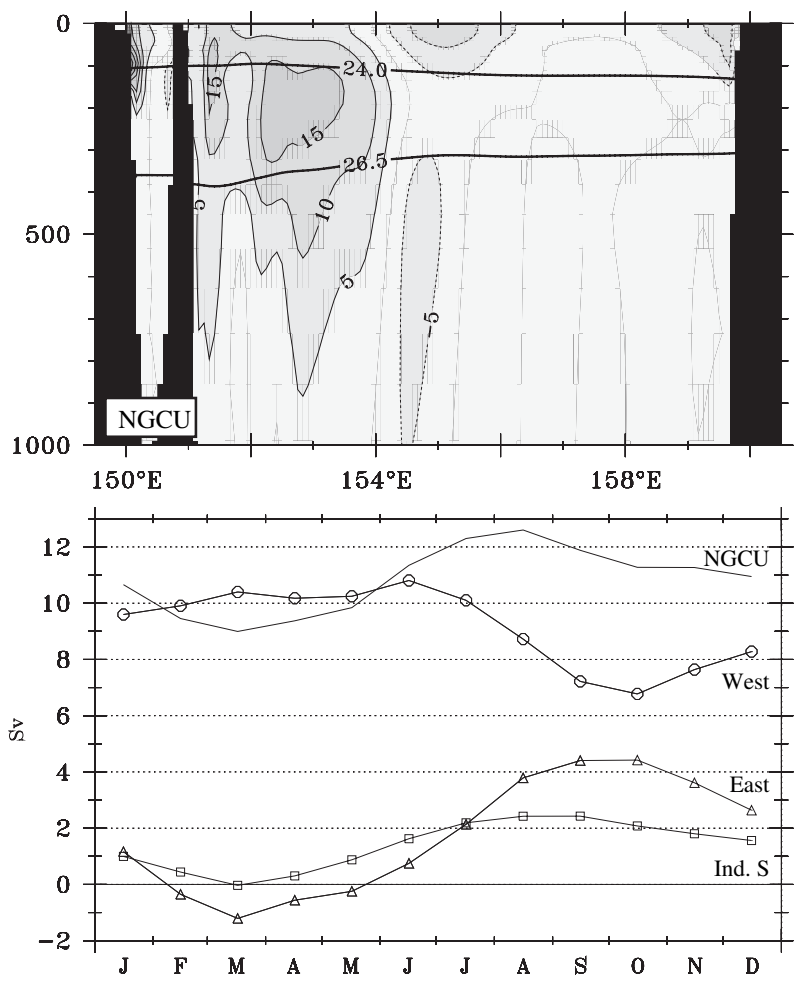

FIG. 10. (a) NGCU velocity section as defined by the northern boundary of box 1 (see Fig. 9). Currents are positive in the direction of the mean flow (northward). The 24.0 and 26.5 isopycnal surfaces are plotted. (b) Annual cycle of the thermocline transports for box 1 sections. The continuous line shows the transport at the northern boundary. The line with circles shows the transport at the western and southwestern sections (west source). The line with triangles shows the transport at the eastern (including Indispensable Strait) and southeastern sections (east source). The line with squares shows the transport at Indispensable Strait.

transport, defined as the outflow across the northern boundary of box 1 west of $154.5^{\circ} \mathrm{E}$, is $11.2 \mathrm{~Sv}$. The mean NGCU is mainly fed by the NQC, with $6.4 \mathrm{~Sv}$ through the western section. Additional transport from the east arrives from both Indispensable Strait $(1.4 \mathrm{~Sv})$ and the NVJ (1.8 Sv). Because part of the NVJ exits the box to the south $(1.5 \mathrm{~Sv})$, only a small part of the NVJ transport directly feeds the NGCU (0.3 Sv), and Indispensable Strait appears as a relatively important pathway feeding the Solomon Sea. A $2.8-\mathrm{Sv}$ flow enters box 1 at $13^{\circ} \mathrm{S}$ between $149.5^{\circ}$ and $154.5^{\circ} \mathrm{E}$ and closes the box 1 transport budget. This transport probably corresponds to leftover parts of both the NVJ and NQC in their complex encounter south of the Louisiades at $155^{\circ} \mathrm{E}$ (Fig. 4a).

Thus, the NGCU has two sources: a major one coming from the west (principally the NQC) and a smaller one from the east (principally the SEC). Because of the recirculation at the southern boundary of box 1 mentioned above, the effective western sources correspond to the transports through both the western and southwestern 


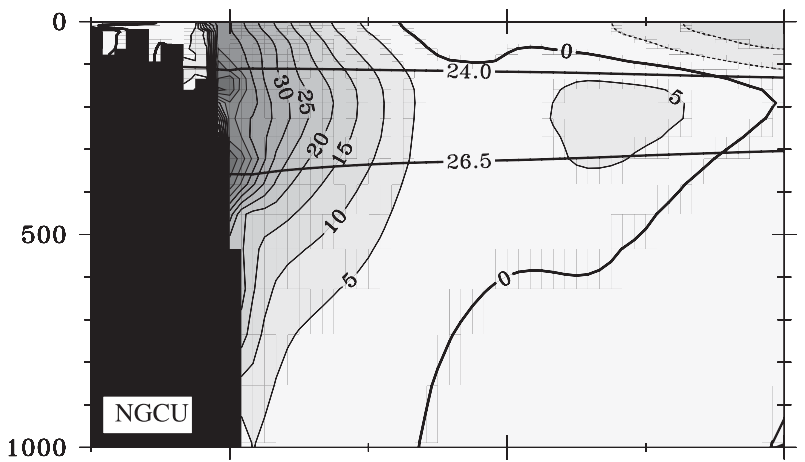

$148^{\circ} \mathrm{E}$

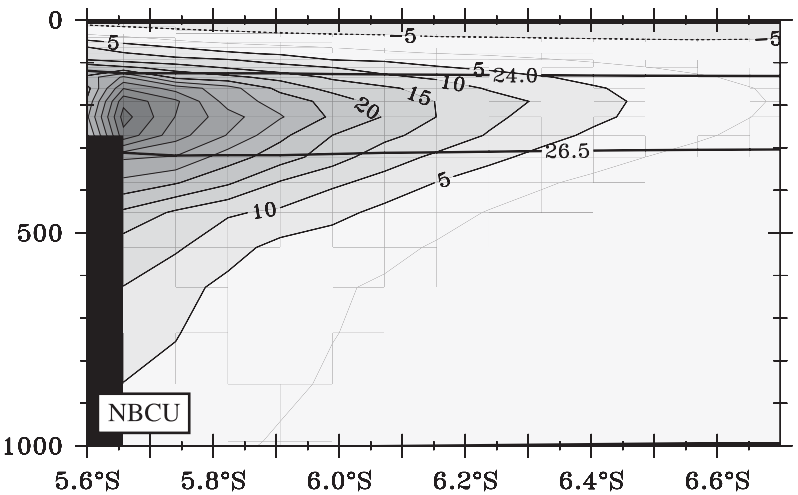

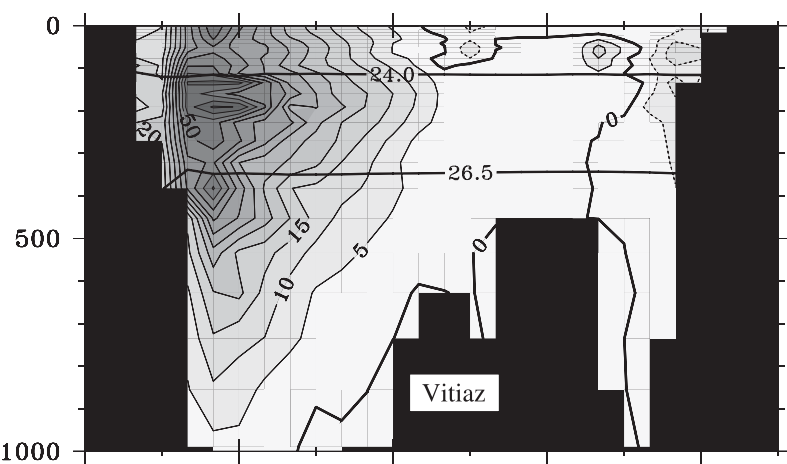
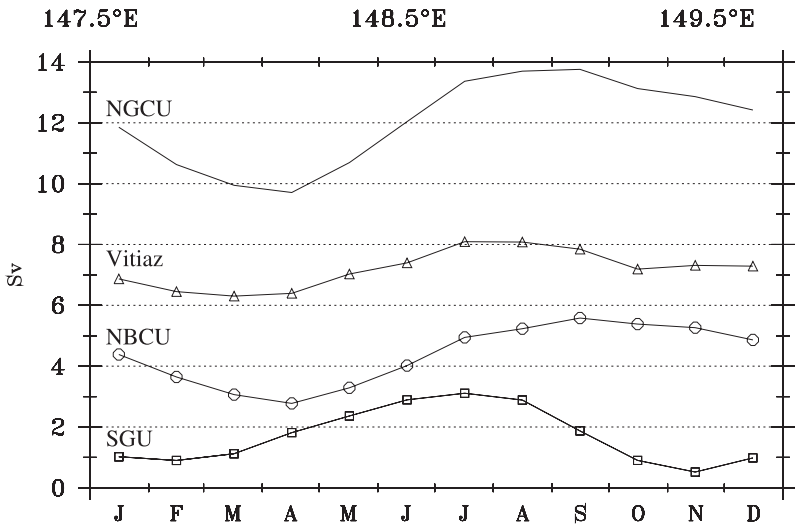

FIG. 11. (top left) NGCU velocity section at the southern boundary of box 2, (top right) NGCU velocity section at Vitiaz Strait, and (bottom left) NBCU velocity section at the eastern boundary of box 2. Currents are positive in the direction of the mean flow (see Fig. 9). The 24.0 and 26.5 isopycnal surfaces are plotted. (bottom right) Annual cycle of the thermocline transports for box 2 sections. The continuous line shows NGCU transport, the line with triangles shows transport through Vitiaz Strait, the line with circles shows NBCU transport, and the line with squares shows SGU transport.

sections of box 1 , whereas the eastern sources correspond to both the eastern (Indispensable Strait plus NVJ) and southeastern sections. Figure 10 shows the time series of the transport of the NGCU, of the western and eastern sources, and of Indispensable Strait. The western and eastern sources are in phase opposition. Maximum transport from the eastern sources, of $4.4 \mathrm{~Sv}$, occurs in September-October, whereas maximum transport from the western sources, of $10.8 \mathrm{~Sv}$, occurs in March-June. The standard deviations of those transports are 2.0 and $1.3 \mathrm{~Sv}$ for the eastern and western sources, respectively. The variability of both sources partly compensates, which explains the relatively low variability of the northern section of box 1 (1.1 Sv; $0.8 \mathrm{~Sv}$ if we only consider the NGCU west of $\left.154.5^{\circ} \mathrm{E}\right)$.

Overall, the NGCU is mainly fed by the NQC. This current's variability partly compensates that generated by the SEC.

\section{b. Box 2: The bifurcation of the NGCU at the entrance to Vitiaz Strait (Fig. 11)}

While flowing equatorward, the NGCU mean transport and its standard deviation $(12.0 \pm 1.4 \mathrm{~Sv})$ slightly increases compared to its original source at $10^{\circ} \mathrm{S}$ (box 1 ). This increase is due to an additional inflow from Solomon Strait (Fig. 9).

At Vitiaz Strait, the NGCU transport splits, with $7.2 \mathrm{~Sv}( \pm 0.6 \mathrm{~Sv})$ flowing through the strait, and $4.4 \mathrm{~Sv}$ ( $\pm 0.9 \mathrm{~Sv}$ ) turning east into the NBCU. As in the section at $10^{\circ} \mathrm{S}$, the NGCU core extends down to at least $500 \mathrm{~m}$, which is below the 26.5 isopycnal at Vitiaz Strait (Fig. 11).

The low variability at Vitiaz Strait may be due to limitation of the transport by the narrowness of the strait, as discussed in section $3 \mathrm{~b}$. The transport phase at Vitiaz Strait leads the upstream NGCU by one month.

A description of the NGCU along the northern coast of New Guinea and in Vitiaz Strait was provided by Lindstrom et al. $(1987,1990)$ using WEPOCS data. They reported a remarkably strong subsurface equatorwardflowing current in Vitiaz Strait, with maximum speeds in excess of $100 \mathrm{~cm} \mathrm{~s}^{-1}, 10 \mathrm{~km}$ offshore New Guinea at 200-m depth, and estimated a Vitiaz Strait volume transport of $14 \mathrm{~Sv}$. Later, during the WOCE program, five moorings were deployed in Vitiaz Strait from March 1992 to March 1993. Using those data, Murray et al. (1995) found that the NGCU flowed northwestward all year 
long, and top-to-bottom transport fluctuated between 14.9 and $19.0 \mathrm{~Sv}$, with a mean of $15.8 \mathrm{~Sv}$ and a maximum transport during the austral winter. In our simulation, the results are comparable to those works. Model NGCU maximum speeds are $95 \mathrm{~cm} \mathrm{~s}^{-1}, 18 \mathrm{~km}$ offshore at 100200-m depth. The model mean 1986-2004 top-to-bottom Vitiaz Strait transport is 14.9 Sv with a maximum transport in August in good agreement with the above-mentioned observations.

The NBCU has never been measured, but its presence has been suspected, both in a modeling study by Inoue and Welsh (1993) and in databased studies (Ridgway et al. 1993; Fine et al. 1994). In the present simulation, at $152^{\circ} \mathrm{E}$, the NBCU core is found at $230-\mathrm{m}$ depth, $10 \mathrm{~km}$ offshore of New Britain, with mean speeds of $60 \mathrm{~cm} \mathrm{~s}^{-1}$. Because the transport variability through Vitiaz Strait is small, the NBCU carries most of the NGCU seasonal variability seen at $10^{\circ} \mathrm{S}$, and it is in phase with the NGCU (minimum in austral fall and maximum in austral spring). Note that the SGU permits an outflow of $1.7 \mathrm{~Sv}$, and its variability is as high as the variability of the NBCU; however, both currents are out of phase.

\section{c. Box 3: Solomon Strait and the NICU's origins (Fig. 12)}

The mean velocities across Solomon Strait show a westward flow entering the Solomon Sea in the surface layers (above the thermocline layer considered here), corresponding to the SEC. In the thermocline, Solomon Strait presents both a large outflow (3.7 Sv) exiting the Solomon Sea along New Ireland, corresponding to the NBCU, and a smaller inflow (1.2 Sv) entering the Solomon Sea along Bougainville (Fig. 1), coming from the SICU. As a result, the net thermocline transport through Solomon Strait is only $2.6 \mathrm{~Sv}$.

The mean NBCU transport in box 2 is $4.4 \mathrm{~Sv}$, of which $1.7 \mathrm{~Sv}$ exits the Solomon Sea in the SGU upstream of Solomon Strait. Thus, the NBCU should transport $2.7 \mathrm{~Sv}$ when arriving in Solomon Strait. However, the NBCU transport in box 3 is stronger, with $3.7 \mathrm{~Sv}$. The strengthening of the NBCU along the New Britain coast is due to the part of the SICU entering the Solomon Sea, which mostly recirculates into the NBCU, while the remainder reinforces the NGCU in the northern Solomon Sea as previously suggested.

In our model, the SICU is confined within $100 \mathrm{~km}$ of the Solomon Islands eastern coast. Its mean speeds are quite low, with core speeds around $20 \mathrm{~cm} \mathrm{~s}^{-1}$ near 200-m depth (which is the depth of maximum SEC at those latitudes). At $6^{\circ} \mathrm{S}$, its mean thermocline transport is $1.5 \mathrm{~Sv}( \pm 0.6 \mathrm{~Sv}), 1.2 \mathrm{~Sv}$ enters the Solomon Sea, and only $0.3 \mathrm{~Sv}$ directly feeds the NICU (Fig. 9).
Box 3 allows quantification of the sources of the NICU's thermocline water. During the WEPOCS oceanographic cruise, Butt and Lindstrom (1994) found an equatorward undercurrent lying within $40 \mathrm{~km}$ of the eastern coast of New Ireland. The alongshore core was located at $235 \mathrm{~m}$ with speed of $60 \mathrm{~cm} \mathrm{~s}^{-1}$. In good agreement with those observations, the NICU in our model has maximum velocities of $65 \mathrm{~cm} \mathrm{~s}^{-1}$ on the 25.5 isopycnal close to the New Ireland coast. The mean thermocline transport across this section is $5.2 \mathrm{~Sv}$ and occurs in the NICU west of $154.5^{\circ} \mathrm{E}$ (Fig. 12). According to these results, the NICU has three sources: the SEC, SICU, and NBCU. The NBCU is the main source of the NICU (3.7 Sv at Solomon Strait) and the direct contribution of the SICU has been estimated to be $0.3 \mathrm{~Sv}$, so the direct SEC contribution is about $1.3 \mathrm{~Sv}$.

The seasonal variability of the SEC thermocline layers transport entering the east side of box 3 is high compared to its mean transport $(1.3 \pm 1.5 \mathrm{~Sv})$. It is worthwhile to note that the SEC's annual cycle at those latitudes is in nearly phase opposition with the NBCU and SICU ones (Fig. 12). This can be understood from a linear dynamics point of view. Because of the speed decrease with latitude of Rossby waves, a downwelling Rossby wave arrives in September-October at the latitudes of the south entrance of the Solomon Sea, whereas an upwelling Rossby wave arrives at $8^{\circ} \mathrm{S}$. Thus, on the south side of the Rossby wave crests, transport anomalies develop, which strengthen the NVJ and weaken the SEC at $5^{\circ} \mathrm{S}$. In response to the SEC weakening near $5^{\circ} \mathrm{S}$ and to the NVJ strengthening, the NBCU has to be anomalously eastward. Six months later, the situation is reversed. Thus, at the latitudes of Solomon Strait, the SEC annual cycle is in nearly phase opposition with that of the NBCU.

\section{d. Box 4: NICU and connection to the EUC (Fig. 13)}

While flowing along New Ireland, the NICU slightly strengthens $(0.4 \mathrm{~Sv})$, receiving mass from the SEC. Its transport for box 4 is $5.6 \mathrm{~Sv}$, with $1.7 \mathrm{~Sv}$ stemming from the SEC (1.3 Sv in box 3 and an extra $0.4 \mathrm{~Sv}$ from box 3 to box 4). Arriving at the northern extremity of New Ireland, the NICU splits quite equally, with $2.6 \mathrm{~Sv}$ flowing westward into the Bismarck Sea and 3.0 Sv retroflected eastward into the EUC (Fig. 9). The westward branch of the NICU continues west to join the NGCU on the northern coast of New Guinea. The retroflection of the $\mathrm{NICU}$ into the EUC near $1^{\circ} \mathrm{S}, 152^{\circ} \mathrm{E}$ is the most direct route for the flow transiting through the Solomon Sea to join the EUC.

The NICU's annual variability is as large as that of the SEC, with a standard deviation of $1.0 \mathrm{~Sv}$. Its transport 

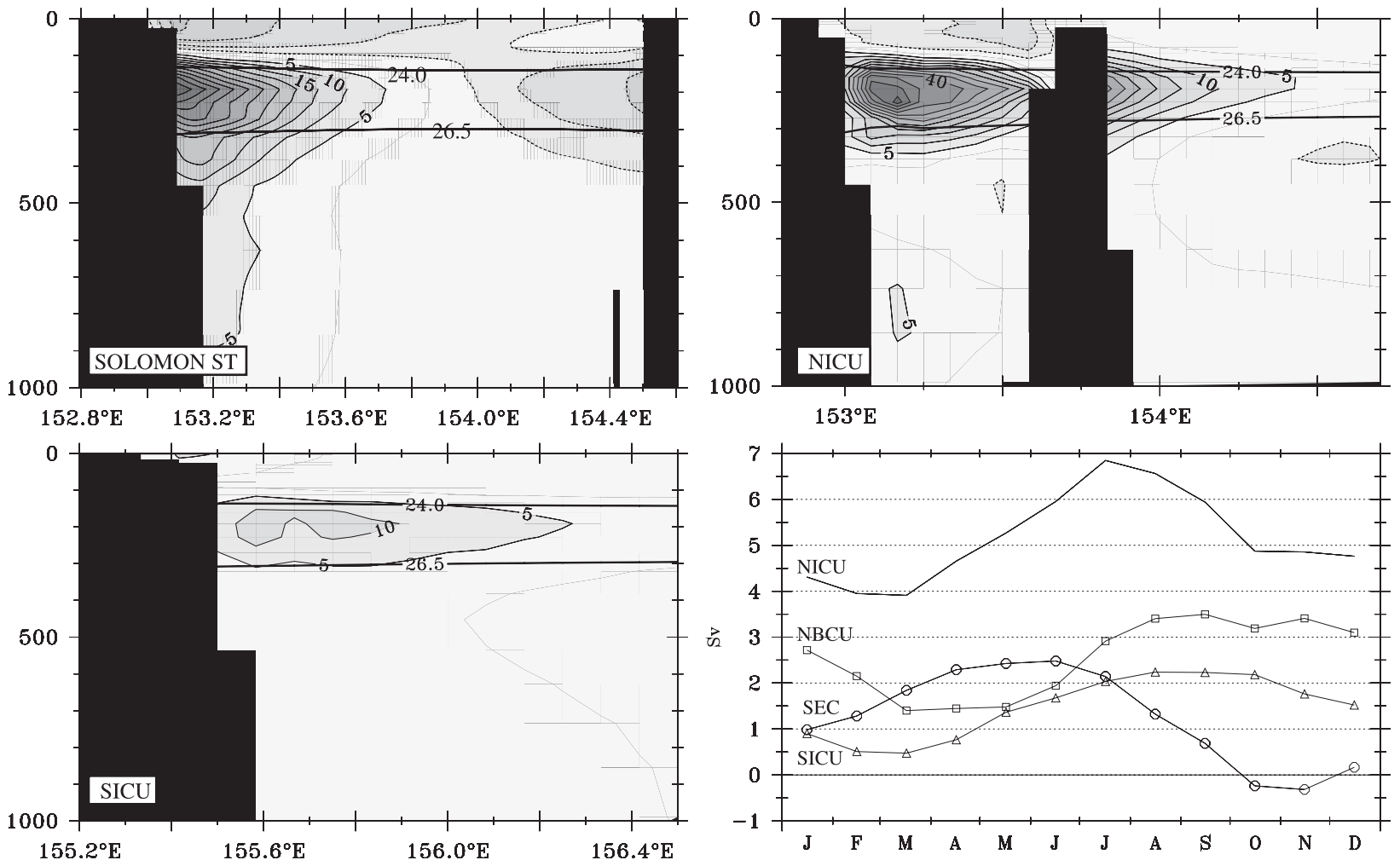

FIG. 12. (top left) Velocity section at Solomon Strait as defined in box 3, (top right) NICU velocity section at the northern boundary of box 3, and (bottom left) SICU velocity section at the southern boundary of box 3. Currents are positive in the direction of the mean flow. The 24.0 and 26.5 isopycnal surfaces are plotted. (bottom right) Annual cycle of the thermocline transports for box 3 sections. The continuous line shows the NICU transport, the line with squares shows NBCU transport, the line with triangles shows SICU transport, and the line with circles shows SEC transport.

is maximum $(7.3 \mathrm{~Sv})$ in July and minimum $(4.5 \mathrm{~Sv})$ in January (Fig. 13), but its two branches do not evolve in phase. The branch connecting with the EUC (standard deviation of $1.0 \mathrm{~Sv}$ ) is largest in July, when the NICU is strengthened by the NBCU, whereas the westward branch of the NICU in the Bismarck Sea (standard deviation of $0.3 \mathrm{~Sv}$ ) is largest in September-October.

\section{Summary and conclusions}

This study aims at a better understanding of the complex pathways followed by the low-latitude western boundary currents (LLWBCs) of the South Pacific Ocean through the multiple islands delimiting the Solomon Sea. The Solomon Sea thermocline circulation plays a key role in the connections between the South Pacific subtropical gyre and the Equatorial Undercurrent (EUC), with potential consequences for the low-frequency modulation of equatorial climate, including El Niño-Southern Oscillation (ENSO). This study takes a first step by examining the seasonal variability.

Our approach is based on the simulation results provided by a $1 / 12^{\circ}$ primitive equation model of the Solomon
Sea interactively embedded in a $14^{\circ}$ regional model of the southwest Pacific, itself embedded in a global model. Model results give per se a schematic view of reality and must be considered with some caution. However, sensitivity studies and data assessment give some confidence in the robustness of our results. Moreover, modeling is currently the only means to study the detailed time and space features of the Solomon Sea circulation.

The detailed circulation appears to be complex, especially because of the intricate bathymetry of the Solomon Sea region, in particular the existence of the $5^{\circ}$ latitude barrier of the Solomon Island chain in front of the continental barrier formed by the PNG coast, and the narrowness of Vitiaz Strait, which prevents the main boundary current from flowing freely north along the coast.

The connection of the southwest Pacific WBCs to the equator involves the bifurcation of the South Equatorial Current (SEC) at the Australian coast to form the equatorward North Queensland Current (NQC), which in turn gives rise to the New Guinea Coastal Undercurrent (NGCU) along the Papua New Guinea coast. Although the NGCU is indeed principally fed by the NQC (more 


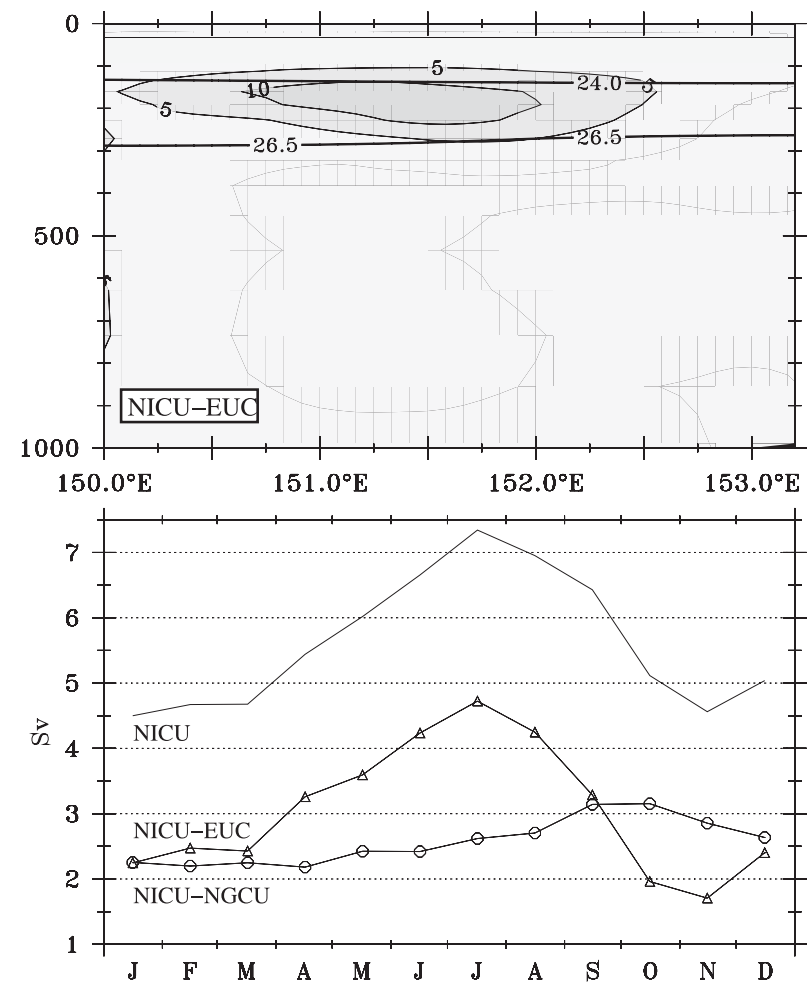

FIG. 13. (a) Velocity section at the northern section of box 4 showing the NICU connection to the EUC. Currents are positive in the direction of the mean flow. The 24.0 and 26.5 isopycnal surfaces are plotted. (b) Annual cycle of the thermocline transports for box 4 sections. The line with circles shows the transport of the westward branch of the NICU (westward section of box 4, NICUNGCU), the line with triangles shows NICU-EUC (equatorward section of box 4) transport, and the continuous line shows NICU transport (NICU-EUC plus NICU-NGCU).

than $57 \%$ of the NGCU water comes from the NQC), there is also a more direct interior route by the SEC through both Indispensable Strait and the North Vanuatu Jet (NVJ), a jet formed by the interaction of the SEC with the Vanuatu Archipelago (Webb 2000; Qiu et al. 2009). South of the Solomon Islands, the NVJ meets the NQC, and both enter the Solomon Sea at the eastern tip of the Louisiade Archipelago to feed the NGCU.

When arriving at the mouth of Vitiaz Strait, the NGCU, which transports around $12 \mathrm{~Sv}$ in the thermocline, splits in two branches. The main branch flows through Vitiaz Strait and continues northwestward along the New Guinea coast, transporting more than $60 \%$ of the NGCU thermocline water. The other branch, undocumented so far and denoted here as the New Britain Coastal Undercurrent (NBCU), flows northeastward along the southern coast of New Britain and exits the Solomon Sea at the St. George's and Solomon Straits. Sensitivity experiments showed that this partition of the NGCU is a consequence of transport limitation through Vitiaz Strait.
Thus, a realistic representation of Vitiaz Strait bathymetry is fundamental to correctly model the Solomon Sea circulation and its connections to the EUC.

The large meridional barrier formed by the Solomon Islands and New Ireland is at the origin of a poorly known system of equatorward WBCs along the east side of these island chains, composed of the Solomon Islands Coastal Undercurrent (SICU) and the New Ireland Coastal Undercurrent (NICU). The NICU is principally fed by the NBCU (67\%) and by the SEC for a thermocline transport of around $5 \mathrm{~Sv}$.

At the northern end of New Ireland, a branch of the NICU turns westward in the Bismarck Sea, whereas another branch retroflects and brings $3 \mathrm{~Sv}$ to the EUC west of $152^{\circ} \mathrm{E}$. This NICU-EUC connection provides the most direct route for subtropical thermocline water to reach the equator via the western boundary, and it carries about $25 \%$ of the total western boundary transport.

The seasonal variability in the domain provides a modulation of the intensity of the main currents, but the phasing of these currents reveals also quite complex features and the influence of different dynamical regimes. The annual march of the trade winds and convergence zones produces equatorial waves that control the EUC variability and therefore its drawing of off-equatorial water during its austral spring-summer surge. The same forcing generates strong Rossby waves in the off-equatorial central Pacific north of $10^{\circ} \mathrm{S}$ that modulate the SEC inflow to the western boundary function of latitude. South of $10^{\circ} \mathrm{S}$, the annual march of the southeast trades is responsible for the spinup and spindown of the subtropical gyre, which in turn generates stationary, in-phase Rossby waves at its equatorward edge (Kessler and Gourdeau 2007). This is what modulates the NVJ and the NQC. The combination of those forcings, as well as their relative phasing, explains the annual cycle of the double WBC system of the Solomon Sea.

We notably found that, although the bulk of the mean NGCU originates from the NQC, the NGCU's seasonal variability is controlled by both the NQC and the NVJ. Moreover, although most of the NGCU transport escapes through Vitiaz Strait, its variability is mainly transmitted to the NBCU, which is maximum in austral spring.

Future studies will include the extension of the present work to interannual and decadal time scales that should be more relevant to understand the role of the WBCs in the low modulation of ENSO. Furthermore, it is of prime importance to know the effective role of the WBC in transmitting anomalies of temperature and salinity originating from the southeast Pacific to the equator. Indeed, the strong western boundary currents of the Solomon Sea associated with its complex bathymetry could enhance vertical turbulent mixing leading to water 
mass transformation at thermocline level. As the time series accumulate over the next few years, these model results could be soon analyzed in light of several field observations currently being realized (such as the repeated section of glider surveys between the Louisiades and Guadalcanal islands) or planned (such as the 201011 SPICE oceanographic cruises).

Acknowledgments. This work was supported by the Centre National d'Etude Spatiales (CNES), the Centre National de Recherche Scientifique (CNRS), and the Institut de Recherche pour le Développement (IRD). Calculations were performed using HPC resources from GENCI-IDRIS (Grant 2009-011279). The authors are grateful to three anonymous reviewers for their helpful comments on this manuscript. We also thank the NOAA/ Pacific Marine Environmental Laboratory for hosting an extended visit by A. Melet and for their work on TAO data (available online at http://www.pmel.noaa.gov). XBT data used in this study were collected and made freely available by the Coriolis project and programs that contribute to it (available online at http://www.coriolis. eu.org).

\section{REFERENCES}

Adcroft, A., C. Hill, and J. Marshall, 1997: Representation of topography by shaved cells in a height coordinate ocean model. Mon. Wea. Rev., 125, 2293-2315.

Barnier, B., and Coauthors, 2006: Impact of partial steps and momentum advection schemes in a global ocean circulation model at eddy-permitting resolution. Ocean Dyn., 56, 543567, doi:10.1007/s10236-006-0082-1.

Blanke, B., and P. Delecluse, 1993: Variability of the tropical Atlantic Ocean simulated by a general circulation model with two different mixed-layer physics. J. Phys. Oceanogr., 23, 1363-1388.

—_, and S. Raynaud, 1997: Kinematics of the Pacific Equatorial Undercurrent: An Eulerian and Lagrangian approach from GCM results. J. Phys. Oceanogr., 27, 1038-1053.

Bratcher, A. J., and B. S. Giese, 2002: Tropical Pacific decadal variability and global warming. Geophys. Res. Lett., 29, 1918, doi:10.1029/2002GL015191.

British Oceanographic Data Centre, 2003: Centenary Edition of the GEBCO Digital Atlas. Intergovernmental Oceanographic Commission and the International Hydrographic Organization. [Available online at http://www.gebco.net/data_and_products/ gebco_digital_atlas/.]

Butt, J., and E. Lindstrom, 1994: Currents off the east coast of New Ireland, Papua New Guinea, and their relevance to regional undercurrents in the western equatorial Pacific Ocean. J. Geophys. Res., 99, 12 503-12 514.

Chang, P., B. Giese, L. Ji, H. Seidel, and F. Wang, 2001: Decadal change in the south tropical Pacific in a global assimilation analysis. Geophys. Res. Lett., 28, 3461-3464.

Chen, S., and B. Qiu, 2004: Seasonal variability of the South Equatorial Countercurrent. J. Geophys. Res., 109, C08003, doi:10.1029/ 2003JC002243.
Couvelard, X., P. Marchesiello, L. Gourdeau, and J. Lefvre, 2008: Barotropic zonal jets induced by islands in the southwest Pacific. J. Phys. Oceanogr., 38, 2185-2204.

Debreu, L., C. Vouland, and E. Blayo, 2008: AGRIF: Adaptive grid refinement in Fortran. Comput. Geosci., 34, 8-13.

Fine, R. A., R. Lukas, F. Bingham, M. J. Warnar, and R. H. Gammon, 1994: The western equatorial Pacific: A water mass crossroads. J. Geophys. Res., 99, 25 063-25 080.

Fukumori, I., T. Lee, B. Cheng, and D. Menemenlis, 2004: The origin, pathway, and destination of Niño-3 water estimated by a simulated passive tracer and its adjoint. J. Phys. Oceanogr., 34, 582-604.

Giese, B. S., S. C. Urizar, and N. S. Fučkar, 2002: Southern Hemisphere origins of the 1976 climate shift. Geophys. Res. Lett., 29, 1014, doi:10.1029/2001GL013268.

Godfrey, J. S., 1975: On ocean spindown I: A linear experiment. J. Phys. Oceanogr., 5, 399-409.

, 1989: A Sverdrup model of the depth-integrated flow for the World Ocean allowing for island circulations. Geophys. Astrophys. Fluid Dyn., 45, 89-112.

Gourdeau, L., W. Kessler, R. Davis, J. Sherman, C. Maes, and E. Kestenare, 2008: Zonal jets entering the Coral Sea. J. Phys. Oceanogr., 38, 715-725.

Holland, M., and M. Raphael, 2006: Twentieth century simulation of the Southern Hemisphere climate in coupled models. Part II: Sea ice conditions and variability. Climate Dyn., 26, 229-245.

Inoue, M., and S. E. Welsh, 1993: Modeling seasonal variability in the wind-driven upper-layer circulation in the Indo-Pacific region. J. Phys. Oceanogr., 23, 1411-1436.

Johnson, G. C., and M. J. McPhaden, 1999: Interior pycnocline flow from the subtropical to the equatorial Pacific Ocean. J. Phys. Oceanogr., 29, 3073-3089.

Kessler, W. S., and L. Gourdeau, 2007: The annual cycle of circulation of the southwest subtropical Pacific, analyzed in an ocean GCM. J. Phys. Oceanogr., 37, 1610-1627.

Kuroda, Y., 2000: Variability of currents off the northern coast of New Guinea. J. Oceanogr., 56, 103-116.

Large, W., and S. Yeager, 2008: The global climatology of an interannually varying air-sea flux data set. Climate Dyn., 33, 341-364, doi:10.1007/s00382-008-0441-3.

Levitus, S., and Coauthors, 1998: Introduction. Vol. 1, World Ocean Database 1998, NOAA Atlas NESDIS 18, 346 pp.

Lindstrom, E., R. Lukas, R. Fine, E. Firing, S. Godgrey, G. Meyers, and M. Tsuchiya, 1987: The western equatorial ocean circulation study. Nature, 330, 533-537.

_ Vitiaz Strait and St. George's Channel, Papua New Guinea. The Physical Oceanography of Sea Straits, 171-189.

Lukas, R., T. Yamagata, and J. McCreary, 1996: Pacific low latitude western boundary currents and the Indonesian Throughflow. J. Geophys. Res., 101, 12 209-12 216.

Luo, J.-J., and T. Yamagata, 2001: Long-term El Niño-Southern Oscillation (ENSO)-like variation with special emphasis on the South Pacific. J. Geophys. Res., 106, 22 211-22 227.

— S. Masson, S. Behara, P. Delecluse, S. Gualdi, A. Navarra, and T. Yamagata, 2003: South Pacific origin of the decadal ENSO-like variation simulated by a coupled GCM. Geophys. Res. Lett., 30, 2250, doi:10.1029/2003GL018649.

Luo, Y., L. Rothstein, R. Zhang, and A. Busalacchi, 2005: On the connection between South Pacific subtropical spiciness anomalies and decadal equatorial variability in an ocean general circulation model. J. Geophys. Res., 110, C10002, doi:10.1029/ 2004JC002655. 
Madec, G., 2008: NEMO ocean engine. Note du Pole de modélisation 27, Institut Pierre-Simon Laplace, 300 pp.

Marks, K. M., and W. H. F. Smith, 2006: An evaluation of publicly available global bathymetry grids. Mar. Geophys. Res., 27, 19-34.

Murray, S., E. Lindstrom, J. Kindle, and E. Weeks, 1995: Transport through Vitiaz Strait. WOCE Notes, No. 7, U.S. WOCE Office, College Station, TX, 21-23.

National Geophysical Data Centre, 2001: ETOPO2 global 2' elevations. U.S. Department of Commerce, National Oceanic and Atmospheric Administration, CD-ROM.

Nonaka, M., and H. Sasaki, 2007: Formation mechanism for isopycnal temperature-salinity anomalies propagating from the eastern South Pacific to the equatorial region. J. Climate, 20, 1305-1315.

Preisendorfer, R., 1988: Principal Component Analysis in Meteorology and Oceanography. Curtis Mobley, $425 \mathrm{pp}$.

Qiu, C., S. Chen, and W. Kessler, 2009: Source of the 70-day mesoscale eddy variability in the Coral Sea and the North Fiji Basin. J. Phys. Oceanogr., 39, 404-420.

Qu, T., and E. J. Lindstrom, 2002: A climatological interpretation of the circulation in the western South Pacific. J. Phys. Oceanogr., 32, 2492-2507.

Ridgway, K. R., J. S. Godfrey, G. Meyers, and R. Bailey, 1993: Sea level response to the 1986-1987 El Niño Southern Oscillation event in the Western Pacific in the vicinity of Papua New Guinea. J. Geophys. Res., 98, 16 387-16 395.

_, J. R. Dunn, and J. L. Wilkin, 2002: Ocean interpolation by weighted least squares: Application to the waters around Australia. J. Atmos. Oceanic Technol., 19, 1357-1375.
Smith, W. H. F., and D. T. Sandwell, 1997: Global sea floor topography from satellite altimetry and ship depth soundings. Science, 277, 1956-1962.

Sokolov, S., and S. Rintoul, 2000: Circulation and water masses of the southwest Pacific: WOCE section 11, Papua New Guinea to Tasmania. J. Mar. Res., 58, 223-268.

Toole, J. M., E. Zou, and R. C. Millard, 1988: On the circulation of the upper waters in the western equatorial Pacific Ocean. Deep-Sea Res., 35, 1451-1482.

Tréguier, A. M., and Coauthors, 2001: An eddy-permitting model of the Atlantic circulation: Evaluating open boundary conditions. J. Geophys. Res., 106, 22 115-22 129.

Tsuchiya, M., 1981: The origin of the Pacific equatorial $13^{\circ} \mathrm{C}$ water. J. Phys. Oceanogr., 11, 794-812.

— R. Lukas, R. Fine, E. Firing, and E. Lindstrom, 1989: Source waters of the Pacific Equatorial Undercurrent. Prog. Oceanogr., 23, 101-147.

Uppala, S. M., and Coauthors, 2005: The ERA-40 Re-Analysis. Quart. J. Roy. Meteor. Soc., 131, 2961-3012.

Wang, B., R. Wu, and R. Lukas, 2000: Annual adjustment of the thermocline in the tropical Pacific Ocean. J. Climate, 13, 596-616.

Webb, D. J., 2000: Evidence for shallow zonal jets in the South Equatorial Current region of the southwest Pacific. J. Phys. Oceanogr., 30, 706-719.

Yeager, S. G., and W. G. Large, 2004: Late-winter generation of spiciness on subducted isopycnals. J. Phys. Oceanogr., 34, $1528-1545$

Yu, X., and M. McPhaden, 1999: Seasonal variability in the equatorial Pacific. J. Phys. Oceanogr., 29, 925-947. 